\title{
Baseline functional connectivity in resting state networks associated with depression and remission status after 16 weeks of pharmacotherapy: A CAN-BIND Report
}

\section{Authors:}

Gwen van der Wijk, MA (1), Jacqueline K. Harris, Msc (2,3), Stefanie Hassel, PhD (4,5), Andrew D. Davis, PhD (6,8), Mojdeh Zamyadi, Msc (6), Stephen R. Arnott, PhD (6), Roumen Milev, MD, PhD (9), Raymond W. Lam, MD (10), Benicio N. Frey, MD, PhD (11,12), Geoffrey B. Hall, PhD (13), Daniel J. Müller, MD, PhD (14,15,16,17), Susan Rotzinger, PhD (18,19), Sidney H. Kennedy, MD (14,17,18,20,21), Stephen C. Strother, PhD (6,7), Glenda M. MacQueen, MD, PhD (4,5), Andrea B.

$$
\text { Protzner, } \mathrm{PhD}(1)(5)(22)
$$

\section{Affiliations:}

1. University of Calgary, Department of Psychology, Calgary, Canada

2. University of Alberta, Department of Computing Science, Edmonton, Canada

3. Alberta Machine Intelligence Institute, Edmonton, Canada

4. University of Calgary, Cumming School of Medicine, Department of Psychiatry, Calgary,

Canada

5. Mathison Centre for Mental Health Research and Education, University of Calgary, Calgary,

Canada

6. Rotman Research Institute, Baycrest Health Sciences, Toronto, Canada

7. University of Toronto, Department of Medical Biophysics, Toronto, Canada

8. Department of Psychology, Neuroscience \& Behaviour, McMaster University, Hamilton, Canada

9. Queen's University, Departments of Psychiatry and Psychology, and Providence Care Hospital,

$$
\text { Kingston, Canada }
$$

10. University of British Columbia, Department of Psychiatry, Vancouver, Canada

11. Department of Psychiatry and Behavioural Neurosciences, McMaster University, Hamilton,

Canada 
12. Mood Disorders Program and Women's Health Concerns Clinic, St. Joseph's Healthcare,

$$
\text { Hamilton, Canada }
$$

13. Department of Psychology, Neuroscience \& Behaviour, McMaster University, and St. Joseph's Healthcare Hamilton, Hamilton, Canada

14. Department of Psychiatry, University of Toronto, Toronto, Canada

15. Campbell Family Mental Health Research Institute, Centre for Addiction and Mental Health,

$$
\text { Toronto, Canada }
$$

16. Department of Pharmacology \& Toxicology, University of Toronto, Toronto, Canada

17. Institute of Medical Sciences, University of Toronto, Toronto, Canada

18. Centre for Mental Health, University Health Network, Toronto, Canada

19. Keenan Research Centre for Biomedical Science, Li Ka Shing Knowledge Institute, St Michael's

$$
\text { Hospital, Toronto, Canada. }
$$

20. Centre for Depression and Suicide Studies, Unity Health Toronto, Toronto, Canada

21. Krembil Research Institute, Toronto Western Hospital, Toronto, Canada

22. Hotchkiss Brain Institute, Calgary, Canada

Key words: Major depressive disorder, functional connectivity, fMRI, default mode network, salience network, cognitive control network

Corresponding author: Gwen van der Wijk

Email: gwen.vanderwijk@ucalgary.ca

Phone: +1-403-220-5025

Address: Department of Psychology, University of Calgary, 2500 University Drive NW, T2N 1N4

Calgary, Alberta, CANADA 
medRxiv preprint doi: https://doi.org/10.1101/2021.01.27.21250490; this version posted January 29, 2021. The copyright holder for this preprint (which was not certified by peer review) is the author/funder, who has granted medRxiv a license to display the preprint in perpetuity.

It is made available under a CC-BY-NC 4.0 International license.

\begin{abstract}
Understanding the neural underpinnings of major depressive disorder (MDD) and its treatment could improve treatment outcomes. While numerous studies have been conducted, findings are variable and large sample replications scarce. We aimed to replicate and extend altered functional connectivity findings in the default mode, salience and cognitive control networks (DMN, SN, and CCN respectively) associated with MDD and pharmacotherapy outcomes in a large, multi-site sample. Resting-state fMRI data were collected from 129 patients and 99 controls through the Canadian Biomarker Integration Network in Depression (CAN-BIND) initiative. Symptoms were assessed with the Montgomery-Åsberg Depression Rating Scale (MADRS). Connectivity was measured as correlations between four seeds (anterior and posterior DMN, SN and $\mathrm{CCN}$ ) and all other brain voxels across participants. Partial least squares, a multivariate statistical technique, was used to compare connectivity prior to treatment between patients and controls, and between patients reaching remission early (MADRS $\leq 10$ within 8 weeks), late (MADRS $\leq 10$ within 16 weeks) or not at all. We replicated previous findings of altered connectivity in the DMN, SN and CCN in patients. In addition, baseline connectivity of the anterior/posterior DMN and SN seeds differentiated patients with different treatment outcomes. Weaker connectivity within the anterior DMN and between the anterior DMN and the $\mathrm{SN}$ and $\mathrm{CCN}$ characterised early remission; stronger connectivity within the SN and weaker connectivity between the SN and the DMN and CCN was related to late remission, of which the weaker $\mathrm{SN}$ - anterior DMN connectivity might specifically be associated with remission to dual pharmacotherapy; and connectivity strength between the posterior DMN and cingulate areas distinguished all three groups, with early remitters showing the strongest connections and non-remitters the weakest. The stability of these baseline patient differences was established in the largest single-site subsample of the data. Our replication and extension of altered connectivity within and between the DMN, SN and CCN highlighted previously reported and new differences between patients with MDD and controls, and revealed features that might predict remission prior to pharmacotherapy.
\end{abstract}

Trial registration: ClinicalTrials.gov: NCT01655706. 


\section{Introduction}

Major depressive disorder (MDD) is a prevalent and debilitating disorder. Although several effective treatments are available, including psychotherapy, pharmacotherapy and neurostimulation therapy, treatment outcomes vary greatly among patients [1,2]. Many neuroimaging studies have investigated brain changes related to MDD pathology and antidepressant treatment, but while the results are promising, inconsistent findings have led to growing concerns about reproducibility [3]. To improve treatment outcomes for patients with MDD, a robust understanding of the characteristics associated with MDD and antidepressant treatment outcomes is essential.

Functional connectivity during rest, as captured by functional magnetic resonance imaging (fMRI) of the brain, has emerged as a potentially informative measure of the neural underpinnings of both the depressive state and its (successful) treatment [4-7]. Based on the more robust findings highlighted in meta-analyses and literature reviews, the three networks that have most consistently been linked to MDD pathology include the default mode network (DMN), the salience network (SN) and the cognitive control network $(\mathrm{CCN})[4,8]$. Core regions of the $\mathrm{DMN}$ are the posterior cingulate cortex $(\mathrm{PCC})$, precuneus, the bilateral angular gyrus and the medial prefrontal cortex (mPFC; [4]). In MDD, the anterior cingulate cortex (ACC) has also been found to be part of the DMN [9]. This network is generally thought to be related to internal processing in conscious participants ([4], see [10] for a discussion on DMN activity during unconscious states). The core regions of the SN include the bilateral insulae, the amygdalae, the temporal poles and the dorsal anterior cingulate cortex (dACC; [4]). It is involved in emotion processing and bottom-up attentional processes (e.g. monitoring for salient stimuli; [5]). Core CCN regions include the bilateral dorsolateral prefrontal cortex (dlPFC), frontal eye fields (FEF), dorsomedial prefrontal cortex (dmPFC) and the posterior parietal cortex (PPC), which together exert top-down control over cognitive and emotional processes [4]. Disturbed connectivity within and between these networks is thought to lead to the abnormal emotion processing and mood regulation in $\operatorname{MDD}[5,11]$. Given the frequency with which these networks are highlighted in previous work and their functional relevance to MDD pathology, we focused on these three resting state networks in our study. 
A meta-analysis and literature review summarizing resting state fMRI connectivity alterations in patients with MDD compared to controls reported that MDD was characterized by stronger connectivity within the DMN, especially anteriorly, between the CCN and DMN, and between the anterior DMN and $\mathrm{SN}[4,5]$. In addition, weaker connectivity within the $\mathrm{CCN}$, between the $\mathrm{SN}$ and the posterior DMN, and between the posterior DMN and CNN was found in patients with MDD compared to controls across studies $[4,5]$. However, the studies included in these papers generally had small samples (typically $<30$ patients) collected at a single site, and variable methodologies, limiting the generalizability of these findings. In addition, MDD itself is a heterogeneous disorder, which likely contributes to the variable findings $[12,13]$. Several authors have called for large, multi-site datasets to increase replicability (e.g. $[14,15])$.

Several studies have also investigated connectivity differences between patients with different treatment outcomes. Here we focus on findings related to pharmacotherapy, which is the most common first-line treatment for MDD. Three reviews indicate that findings often include the same three networks as mentioned above, most commonly showing a decrease in connectivity within the DMN, an increase in connectivity within the $\mathrm{CCN}$ and between frontal $(\mathrm{CCN})$ areas and limbic $(\mathrm{SN})$ regions with treatment [68]. However, the authors of these reviews emphasize that results vary greatly among studies, and that similar issues to those raised in the previous paragraph prevent robust conclusions and limit translational relevance [6-8]. Indeed, a recent meta-analysis was not able to detect any resting state connectivity patterns predictive of treatment response to pharmacotherapy [16]. They included only studies examining the association between symptom improvement with treatment and baseline brain-wide resting state connectivity at the voxel level, leaving six studies for their analysis. In addition to underlining the variability in findings to date, this highlights the scarcity of studies looking specifically at baseline fMRI connectivity predictors of treatment outcomes, which could be especially informative for clinical practice.

In the current study, we made use of a relatively large, multi-site resting state fMRI dataset to replicate and extend previous findings of connectivity alterations in patients with MDD compared to controls, and differences in connectivity prior to treatment among patients with differing outcomes. The 
medRxiv preprint doi: https://doi.org/10.1101/2021.01.27.21250490; this version posted January 29, 2021. The copyright holder for this preprint (which was not certified by peer review) is the author/funder, who has granted medRxiv a license to display the preprint in perpetuity.

It is made available under a CC-BY-NC 4.0 International license .

dataset was collected as part of the Canadian Biomarker Integration Network in Depression 1 (CANBIND-1) study and included controls and patients diagnosed with MDD, who were treated for 16 weeks with escitalopram, and an add-on of aripiprazole after 8 weeks if symptoms decreased less than 50\% [17, 18]. Depression symptoms were monitored using the Montgomery-Åsberg Depression Rating Scale (MADRS; [19]). Patients were divided into three groups: early remitters reached a score of $\leq 10$ on the MADRS by week 8 , late remitters reached this threshold after 16 weeks, and non-remitters did not reach remission by the end of the 16-week trial. Resting state fMRI data were recorded before the start of treatment. Connectivity between key nodes from the DMN, SN and CCN, and the rest of the brain was compared between groups using partial least squares (PLS; [20]). We expected to replicate previous patient-control differences in connectivity within and between the DMN, SN and CCN, and to find differences among patients with different treatment outcomes in these same networks.

\section{Methods}

\section{Participants \& treatment}

Study participants included 108 controls and 200 patients ( $70 \& 126$ females, respectively) with a primary diagnosis of major depressive disorder (MDD), who were recruited from six academic health centres across Canada (University of British Columbia, University of Calgary, McMaster University, Centre for Addiction and Mental Health, Toronto General Hospital, Queen's University) as part of the CAN-BIND-1 study $[17,18]$. Briefly, patients were between 18-60 years of age, spoke sufficient English to complete the study, met the criteria for a major depressive episode according to the DSM-IV-TR, as assessed with the Mini International Neuropsychiatric Interview (MINI, [21]), had symptom scores of $\geq 24$ on the Montgomery-Åsberg Depression Rating Scale ([MADRS]; [19]) and their current episode lasted 3 months or longer. Patients were excluded if they met the diagnostic criteria of bipolar-I or -II disorder or any other primary psychiatric or personality disorder (except for generalized anxiety disorder and social anxiety disorder), experienced psychotic symptoms in the current episode, had a history of neurological 
medRxiv preprint doi: https://doi.org/10.1101/2021.01.27.21250490; this version posted January 29, 2021. The copyright holder for this preprint (which was not certified by peer review) is the author/funder, who has granted medRxiv a license to display the preprint in perpetuity. It is made available under a CC-BY-NC 4.0 International license .

disorders, head trauma or other unstable medical conditions, had a high risk of suicide or a hypomanic switch, experienced substance dependence/abuse in the last 6 months, were currently pregnant or breastfeeding, showed previous non-response to four adequate pharmacotherapy interventions, had a previous unfavorable response to escitalopram or aripiprazole or had any contraindications to MRI. Patients who had been taking antidepressant medication prior to participation went through a washout period (lasting at least 5 half-lives). Controls were between 18-60 years of age, had no psychiatric or unstable physical health diagnosis, no history of neurological disorders, head trauma or other unstable medical conditions, and spoke sufficient English to complete the study.

Ethics approval was obtained from all participating centres. The ethics committees include: University of British Columbia Clinical Research Ethics Board (Vancouver); University of Calgary Conjoint Health Research Ethics Board (Calgary); University Health Network Research Ethics Board (Toronto); Centre for Addiction and Mental Health Research Ethics Board (Toronto); Hamilton Integrated Research Ethics Board (Hamilton); Queen’s University Health Sciences and Affiliated Teaching Hospitals Research Ethics Board (Kingston). The participants provided written, informed consent for all study procedures.

All patients were given escitalopram for the first 8 weeks of the study. The initial dose was $10 \mathrm{mg} / \mathrm{d}$, which was increased to $20 \mathrm{mg} / \mathrm{d}$ if MADRS symptom scores did not drop by $20 \%$ after two weeks or $50 \%$ after four weeks. Patients who improved less than $50 \%$ over 8 weeks were given a flexibly dosed add-on of aripiprazole (2-10mg/d) for an additional 8 weeks. Patients who improved 50\% or more remained on their effective dose of escitalopram. Treating psychiatrists could prescribe lower doses for patients who did not tolerate higher doses, and the use of non-psychotropic medications for stable conditions, non-prescription analgesics, supplementals, vitamins and oral contraceptives were allowed at the discretion of the study psychiatrist.

Depression symptoms were assessed with the MADRS, using the structured interview guide (SIGMA) to enhance reliability [22], every two weeks during treatment. For the group analyses, patients were assigned to one of three groups based on whether, and when, they reached remission, which was 
defined as having a MADRS score $\leq 10$, roughly equivalent to the clinical consensus of a cut-off score of $\leq 7$ on the Hamilton Rating Scale for Depression [23]. Remission status was chosen as the main outcome measure for this analysis because this is the ultimate treatment goal, as residual symptoms can lead to significant morbidity [24-26]. Patients who achieved remission at 8 weeks of treatment and maintained this at 16 weeks were considered early remitters (ER), patients who reached this threshold at 16 weeks were considered late remitters (LR), and patients whose MADRS scores were above 10 throughout the 16 weeks were considered non-remitters (NR). Patients who reached remission at 8 weeks, but then relapsed by week $16(\mathrm{~N}=6)$ were not included. An additional 64 participants were excluded due to; treatment not being initiated $(\mathrm{N}=10)$, missing clinical data $(\mathrm{N}=23)$ and missing fMRI data or poor fMRI data quality $(\mathrm{N}=31)$, leaving a sample of 129 patients for analysis. From the control sample, 9 participants were excluded due to poor fMRI data quality. The characteristics of the patient and control groups, as well as ER, LR, and NR patient groups are presented in Table 1 and Table 2, respectively. Statistical differences were assessed in Excel, and any missing individual data points were replaced by the average of their allocated group (e.g. controls or early remitters). The characteristics for which there were missing data points are marked in Table 1 and Table 2, and for each of these, there were no more than three individuals with missing data per group.

Table 1. Characteristics of Controls and Patients with MDD (Mean \pm SD), and their Statistical Differences

\begin{tabular}{lccc} 
& $\begin{array}{c}\text { Controls } \\
(\mathbf{N}=\mathbf{9 9})\end{array}$ & $\begin{array}{c}\text { Patients with MDD } \\
(\mathbf{N}=\mathbf{1 2 9})\end{array}$ & $\begin{array}{c}\text { Statistical } \\
\text { difference }\end{array}$ \\
\hline Sex & 64 female $(65 \%), 35$ male & 81 female $(63 \%), 48$ male & $\chi^{2}(3)=0.1$, \\
& $(35 \%)$ & $(37 \%)$ & $p=.77$ \\
Age (years) & $33.0 \pm 10.6$ & $35.1 \pm 12.2$ & $\mathrm{t}(223)=1.4$, \\
& (range: $18-60)$ & (range: $18-61)$ & $p=.15$
\end{tabular}


Site

Education (years) ${ }^{\mathrm{a}}$

Race/Ethnicity

Handedness

Current marital status
5 CAM (5\%), $16 \mathrm{MCU}(16 \%)$
$12 \mathrm{UBC}(12 \%), 18 \mathrm{TGH}$
$(18 \%), 12 \mathrm{QNS}(12 \%), 34$

$$
\text { UCA }(34 \%)
$$

$$
18.5 \pm 2.3
$$

1 Aboriginal (1\%), 1 Arab (1\%), 9 East Asian (9\%), 3

Latin American/Hispanic

(3\%), 11 South Asian (11\%),

3 Southeast Asian (3\%), 69

White (70\%), 4 Other (4\%), 2

Prefer not to answer (2\%)

$$
\begin{gathered}
11 \text { left (11\%), } 85 \text { right }(86 \%) \text {, } \\
3 \text { ambidextrous }(3 \%)
\end{gathered}
$$

55 never married (56\%), 2 separated (2\%), 27 married (27\%), 5 divorced (5\%), 9 domestic partnership (9\%), 1 widowed (1\%)
$5 \mathrm{CAM}(4 \%), 25 \mathrm{MCU}(19 \%), \quad \chi^{2}(5)=20.0$, $46 \mathrm{UBC}(36 \%), 20 \mathrm{TGH}$ (16\%), 9 QNS (7\%), 24 UCA $(19 \%)$ $\mathrm{p}=.001 *$

$16.9 \pm 2.1$

2 Aboriginal (2\%), 1 Arab (1\%), 4 Black (3\%), 8 East Asian (6\%), 2 Jewish (2\%), 9 Latin American/Hispanic (7\%), 4 South Asian (3\%), 5 Southeast Asian (4\%), 103 White (80\%), 4 Other (3\%)

12 left (9\%), 113 right (88\%), 4 ambidextrous (3\%)

68 never married (53\%), 10 separated (8\%), 29 married (22\%), 10 divorced (8\%), 9 domestic partnership (7\%), 3 widowed $(2 \%)$

* significant at $\mathrm{p}<.05$. MADRS $=$ Montgomery-Åsberg Depression Rating Scale; MDD = major depressive disorder; $\mathrm{CAM}=$ Centre for Addiction and Mental Health; $\mathrm{MCU}=\mathrm{McMaster}$ University; $\mathrm{UBC}=$ University of British Columbia; TGH = Toronto General Hospital; QNS = Queen's University; $\mathrm{UCA}=$ University of Calgary, $\mathrm{NA}=$ not applicable. ${ }^{\mathrm{a}}$ One missing data point from a patient was replaced by the group average. ${ }^{b}$ Statistical comparison was not conducted due to one or more categories having insufficient samples to perform a reliable test.

Table 2. Characteristics of Early Remitters, Late Remitters and Non-Remitters to Antidepressant Pharmacotherapy (Mean \pm SD), and their Statistical Differences

\begin{tabular}{lcccc} 
& $\begin{array}{c}\text { Early remitters } \\
(\mathbf{N}=\mathbf{3 6})\end{array}$ & $\begin{array}{c}\text { Late remitters } \\
(\mathbf{N}=\mathbf{4 6})\end{array}$ & $\begin{array}{c}\text { Non-remitters } \\
\mathbf{( N = 4 7 )}\end{array}$ & $\begin{array}{c}\text { Statistical } \\
\text { difference }\end{array}$ \\
\hline Sex & 23 female $(64 \%)$, & 30 female $(65 \%)$, & 28 female $(60 \%)$, & $\chi^{2}(3)=0.3$, \\
13 male $(36 \%)$ & 16 male $(35 \%)$ & 19 male $(40 \%)$ & $p=.84$ \\
Age (years) & $34.6 \pm 11.7$ & $34.3 \pm 12.1$ & $36.4 \pm 12.9$ & $\mathrm{~F}(2,126)=0.4$,
\end{tabular}


(range: 21-59)

Site

Education (years) ${ }^{\mathrm{a}}$

Race/Ethnicity

Current marital status

Duration of current episode (months) ${ }^{\mathrm{a}}$

Number of previous MDD episodes ${ }^{\mathrm{a}}$

Baseline MADRS score

\section{Handedness}

$\begin{array}{ccc}\text { 1 CAM (3\%), } 8 & \text { 1 CAM (2\%), 11 } & \text { 3 CAM (6\%), } 6 \\ \text { MCU (22\%), 16 } & \text { MCU (24\%), 12 } & \text { MCU (13\%), 18 } \\ \text { UBC (44\%), 3 } & \text { UBC (26\%), 8 } & \text { UBC (38\%), } 9 \\ \text { TGH (8\%), 2 QNS } & \text { TGH (17\%), 4 QNS } & \text { TGH (19\%), 3 QNS } \\ (6 \%), 6 \text { UCA }(2 \%) & (9 \%), 10 \text { UCA } & (6 \%), 8 \text { UCA 17\%) }\end{array}$

(22\%)

$$
17.1 \pm 2.3
$$

$16.7 \pm 2.1$

$16.9 \pm 2.0$

1 Black (3\%), $3 \quad 1$ Aboriginal (2\%),

1 Aboriginal (2\%), East Asian (8\%), 2

1 Arab (2\%), 2 East Latin

American/Hispanic

(6\%), 1 South

Asian (3\%), 1

Southeast Asian

(3\%), 28 White

(78\%), 2 Other $(6 \%)$
Asian (4\%), 2

Jewish (4\%), 4

Latin

American/Hispanic (9\%), 1 South

Asian (2\%), 1

Southeast Asian

(2\%), 36 White

(78\%), 1 Other

(2\%)
3 left (8\%), 33 right 3 left (7\%), 42 right (92\%)

18 never married (50\%), 3 separated (8\%), 9 married (25\%), 3 divorced $(8 \%), 2$ domestic partnership (6\%), 1 widowed (3\%)

$$
25.5 \pm 29.6
$$

(range: 2-131)

$$
3.3 \pm 3.0
$$

(range: 0-13)

$26.6 \pm 4.3$
(91\%), 1 ambidextrous (2\%)

28 never married (61\%), 4 separated

(9\%), 8 married (17\%), 1 divorced (2\%), 3 domestic partnership (7\%), 2 widowed (4\%)

$$
23.0 \pm 30.9
$$

(range: 1-130)

$$
3.1 \pm 3.1
$$

(range: 0-15)

$30.9 \pm 5.3$
6 left (13\%), 38 right (81\%), 3 ambidextrous $(6 \%)$

22 never married (47\%), 3 separated (6\%), 12 married (26\%), 6 divorced (13\%), 4 domestic partnership (9\%)

$$
37.2 \pm 40.4
$$
(range: 2-151)

$$
3.3 \pm 4.1
$$

(range: 0-20)

$30.4 \pm 5.6$
$\mathrm{F}(2,126)=0.2$,
$p=.80$ $p=.67$

$\mathrm{NA}^{\mathrm{b}}$
$\mathrm{NA}^{\mathrm{b}}$

$$
p=.80
$$

$\mathrm{NA}^{\mathrm{b}}$

$\mathrm{NA}^{\mathrm{b}}$
$\mathrm{F}(2,126)=2.2$, $p=.11$

$\mathrm{F}(2,126)=0.04$, $p=.96$

$\mathrm{F}(2,126)=7.9$, $p=.001 *$ 


\begin{tabular}{|c|c|c|c|c|}
\hline $\begin{array}{l}\text { MADRS after } 8 \\
\text { weeks of treatment }\end{array}$ & $4.8 \pm 3.1$ & $18.5 \pm 5.6$ & $23.4 \pm 8.3$ & $\begin{array}{c}\mathrm{F}(2,126)=94.4 \\
p<.001^{*}\end{array}$ \\
\hline $\begin{array}{l}\text { MADRS after } 16 \\
\text { weeks of treatment }\end{array}$ & $3.2 \pm 3.0$ & $5.5 \pm 3.0$ & $19.3 \pm 6.3$ & $\begin{array}{c}\mathrm{F}(2,126)=163.8 \\
p<.001^{*}\end{array}$ \\
\hline Treatment regimen & $36 \operatorname{ESC}(100 \%)$ & $\begin{array}{c}13 \mathrm{ESC} ; 33 \\
\mathrm{ESC}+\mathrm{ARI}\end{array}$ & $\begin{array}{l}5 \mathrm{ESC} ; 42 \\
\mathrm{ESC}+\mathrm{ARI}\end{array}$ & $\begin{array}{c}\chi^{2}(2)=72.3 \\
p<.001^{*}\end{array}$ \\
\hline
\end{tabular}

* significant at $\mathrm{p}<.05$. MADRS $=$ Montgomery-Åsberg Depression Rating Scale; MDD = major depressive disorder; CAM = Centre for Mental Health and Addiction; MCU = McMaster University; $\mathrm{UBC}=$ University of British Columbia; TGH = Toronto General Hospital; QNS = Queen's University; $\mathrm{UCA}=$ University of Calgary; $\mathrm{ESC}=$ escitalopram; $\mathrm{ARI}=$ aripiprazole; $\mathrm{NA}=$ not available. ${ }^{\mathrm{a}}$ Missing data points (max. 3 per group) from individual participants were replaced by the group average.

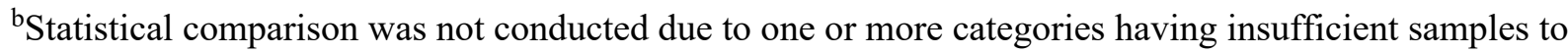
perform a reliable test.

\section{MRI data acquisition and preprocessing}

The structural and functional MRI scans used in this study were collected before the start of treatment. Resting-state fMRI scans were 10 minutes long, during which patients were asked to relax, have their eyes open, and focus on a fixation cross. A subgroup of 104 participants (64 patients and 40 controls) also performed an affective go/no-go task, lasting about 10 minutes. During the task, participants made go/nogo responses to stimuli presented on images containing affective content (see [27] for a detailed description of the task). Task instructions, stimulus presentation and task support materials were standardized across sites to ensure consistency. E-Prime version 2.0 (Psychology Software Tools, Sharpsburg, PA, USA) was used to record behavioural data. In the current study, go/no-go task data were only used for regions of interest (ROI) or "seed" selection (see Seed selection below).

Detailed information on the CAN-BIND MRI protocols can be found in MacQueen et al. [28]. Four different models of MRI scanners, all using 3.0 Tesla MRI systems with multicoil phased-array head coils, were used for data collection (Discovery MR750 3.0T, GE Healthcare; Signa HDxt 3.0T, GE Healthcare; MAGNETOM TrioTim, Siemens Healthcare; Achieva 3.0T, Philips Healthcare). To ensure 
medRxiv preprint doi: https://doi.org/10.1101/2021.01.27.21250490; this version posted January 29, 2021. The copyright holder for this preprint (which was not certified by peer review) is the author/funder, who has granted medRxiv a license to display the preprint in perpetuity. It is made available under a CC-BY-NC 4.0 International license .

data could be validly aggregated across sites, thorough quality control and standardization procedures were applied (see [17] for details). The anatomical scans were obtained using a whole-brain T1-weighted 'magnetization prepared gradient echo sequence with the following parameters: voxel dimensions (in $\mathrm{mm}$ ) $=1 \times 1 \times 1$, echo time $(\mathrm{TE})=2.2-2.9 \mathrm{~ms}$, repetition time $(\mathrm{TR})=6.2-1900 \mathrm{~ms}$, inversion time $(\mathrm{TI})=450-950$ $\mathrm{ms}$, flip angle $=8$ or $15^{\circ}$, field of view $(\mathrm{FOV})=240-256 \mathrm{~mm}$, matrix $=240 \times 240$ or $256 \times 256$, number of slices $=176-192$. The large range in TR was due to Siemens scanners reporting very different values for their proprietary sequence compared to GE and Philips, however image parameters were visually optimized to produce similar contrast across scanners. To aid the confirmation of participant orientation, a small Vitamin E capsule was used as a stereotactic marker by placing it at the right temple during recording. Functional scans were acquired with a whole-brain $\mathrm{T} 2 *$-sensitive blood oxygenation level dependent (BOLD) echo planar imaging (EPI) series, with the following parameters: voxel dimensions (in $\mathrm{mm})=4 \mathrm{x} 4 \mathrm{x} 4$, echo time $(\mathrm{TE})=25$ or $30 \mathrm{~ms}$, repetition time $(\mathrm{TR})=2 \mathrm{~s}$, flip angle $=75^{\circ}$ or $90^{\circ}$, field of view $(\mathrm{FOV})=256 \mathrm{~mm}$, matrix $=64 \times 64$, number of slices $=34-40$.

The resting state fMRI data were preprocessed with the OPPNI pipeline ([29, 30]; software available at https://github.com/raamana/oppni) using the following steps: 1) the volume with the least amount of head displacement was determined using a principal component analysis (PCA) and all volumes were registered to this volume with rigid-body motion correction (MOTCOR) via AFNI's 3dvolreg; 2) significant outlier volumes were identified, removed and replaced by interpolated values using neighbouring volumes through censoring (CENSOR) as implemented in [31] (software available at: nitrc.org/projects/spikecor_fmri); 3) slice-timing correction (TIMECOR) was performed with Fourier interpolation via AFNI's 3dTshift; 4) spatial smoothing across MRI scanners at different sites was matched using the 3dBlurToFWHM module in AFNI to smooth the fMRI images to the smoothness level of FWHM=6mm in three directions $(\mathrm{x}, \mathrm{y}, \mathrm{z}) ; 5)$ AFNI's 3dAutomask algorithm was used to obtain a binary mask excluding non-brain voxels using default parameter settings, the resultant mask was applied to all EPI volumes prior to subsequent pipeline steps; 6) neuronal tissue masking was performed by estimating a probabilistic mask to reduce the variance contribution of non-neuronal tissues in the brain (macro- 
medRxiv preprint doi: https://doi.org/10.1101/2021.01.27.21250490; this version posted January 29, 2021. The copyright holder for this preprint (which was not certified by peer review) is the author/funder, who has granted medRxiv a license to display the preprint in perpetuity.

It is made available under a CC-BY-NC 4.0 International license .

vasculature, ventricles) using the first part of the PHYCAA+ algorithm to estimate task-run and subjectspecific neural tissue masks ([32]; software available at nitrc.org/projects/phycaa_plus); 7) several nuisance regressors (low frequency temporal trends, head motion effects and global signal modulations) were calculated and then regressed-out from the data concurrently via multiple linear regression [33-35]; 8) physiological noise components were estimated and removed through data-driven physiological correction (PHYPLUS) using the second part of the data-driven PHYCAA+ algorithm ([32]; software at nitrc.org/projects/phycaa_plus); 9) low-pass filtering (LOWPASS) was carried out using a linear filter to remove BOLD frequencies above $0.10 \mathrm{~Hz} ; 10$ ) spatial normalization to a structural template (sNORM) was carried out with all scans aligned to the MNI152 template (4mm resolution) using two transformations (fMRISubj -> MRISubj, and MRISubj $\rightarrow$ MNITemp, combined into one aggregated transform) via FSL's FMRIB's Linear Image Registration Tool (FLIRT) module.

The same steps were performed for the task fMRI data, except that no corrections were applied for global signal modulations, physiological noise components or higher frequency BOLD signals. After the OPPNI pipeline, the EPInorm strategy was used for additional spatial normalization on both the resting-state and task fMRI data, as this was shown to consistently reduce variability across participants and lower estimates for co-registration distances among participants [36]. Briefly, the data were registered directly to a cohort-specific EPI template using an affine followed by a nonlinear transformation. Only voxels in the grey matter, as determined by a grey matter mask, were included in the analyses. To account for potential differences in signal quality and tissue coverage, voxels from the grey matter mask were excluded from analysis on the basis of signal-to-noise ratio (SNR, voxel-wise intensity mean over the imaging time-course, divided by the standard deviation) where voxels were excluded if the calculated SNR was less than 100 in at least $5 \%$ of participants [37]. In our analysis this resulted in the exclusion of 2227 of the 17965 voxels originally in the grey matter mask. 
medRxiv preprint doi: https://doi.org/10.1101/2021.01.27.21250490; this version posted January 29, 2021. The copyright holder for this preprint (which was not certified by peer review) is the author/funder, who has granted medRxiv a license to display the preprint in perpetuity.

It is made available under a CC-BY-NC 4.0 International license .

\section{Seed selection}

Four seeds were selected for analysis from the anterior cingulate cortex (ACC), the posterior cingulate cortex (PCC), the insula and the dorsolateral prefrontal cortex (dlPFC), because of their prominent role in three important networks associated with MDD pathology and antidepressant treatment response, namely the anterior DMN, posterior DMN, SN and CCN, respectively [4, 6-8]. Two seeds were selected from the DMN, as the anterior and posterior sections of this network have been found to show distinct alterations in response to antidepressant treatment [38].

The selection of specific seed coordinates was based on analyses contrasting task and resting state BOLD activity in the subgroup of participants who performed the affective go/no-go task. As the affective go/no-go task has been found to increase activation in both the $\mathrm{SN}$ and the CCN compared to rest $[39,40]$, the voxels with the most stable increase in activity (as indicated by bootstrap ratios, see Data analysis with PLS) during the task within the insula and dIPFC were selected as seeds for the SN and $\mathrm{CCN}$. In contrast, the voxels showing the most stable increase in activation during rest compared to the task within the ACC and PCC were selected as the seeds for the anterior and posterior DMN. The average activation of the seed voxels and their immediate neighbours was extracted and used to examine functional connectivity between these regions of interest (ROIs) and the rest of the brain through correlation analyses.

This procedure was conducted twice to make the seed locations as representative as possible of the overall networks for the participants included in each of our two series of analyses: first for controls and patients together, to select the seeds for the patient-control comparisons, and then for patients only, to select the seeds for the comparisons between early, late and non-remitters. MDD and remission status were not considered in these seed selection analyses (i.e. participants were grouped together), to prevent seed selection from being influenced by group effects. Of note, the selected seeds were highly similar in both cases, except for the dlPFC seed (MNI coordinates patients \& controls: ACC: [0 48 -4]; PCC: [0 -60 28]; Insula: [-40 20 0]; dlPFC: [-48 16 32]; MNI coordinates patients only: ACC: [0 48 -4]; PCC: [0 -60 28]; Insula: [-40 20 4]; dlPFC: [-52 28 28]). 
medRxiv preprint doi: https://doi.org/10.1101/2021.01.27.21250490; this version posted January 29, 2021. The copyright holder for this preprint (which was not certified by peer review) is the author/funder, who has granted medRxiv a license to display the preprint in perpetuity.

It is made available under a CC-BY-NC 4.0 International license .

Data analysis with partial least squares (PLS)

Statistical analysis of functional connectivity was performed using the PLS Graphic User Interface version 6.1311050 (Rotman Research Institute, Ontario, Canada, http://www.rotman-baycrest.on.ca/pls) in MATLAB 2012a (The MathWorks, Inc., Natick, Massachusetts). PLS is a multivariate statistical technique that enables the detection of group and/or condition differences in the association between variables of interest and whole-brain activity patterns [41]. By entering the average BOLD activity extracted from the ROIs as variables of interest, we were able to examine functional connectivity as quantified by the correlations between the average activity in the ROIs and all other voxels of the brain across participants. PLS analyses identify latent variables (LVs), i.e. connectivity patterns highlighting similarities and/or differences between groups (MDD \& controls/ER, LR \& NR), that explain the largest amount of variance in the data. Each LV is made up of three components. The first is the singular value, which represents the strength of the effect expressed in the LV. The second contains the condition loadings, which indicate the contrast between groups as highlighted by the LV. The third component holds the element loadings, which describe where in the brain the connectivity differences identified by the LV are expressed.

The statistical assessment of LVs is done at two levels. First, the significance of the overall pattern is examined through permutation testing. Briefly, the data are randomly shuffled between groups and PLS analysis is then performed on the shuffled data for each permutation. LVs are considered significant when the singular value is more extreme than $95 \%$ of the singular values obtained from the shuffled data. We performed 1000 permutations per analysis. Second, bootstrap resampling is used to determine the consistency of the identified spatial pattern across participants. In this process, PLS analyses are repeated with different subsamples, building a distribution of loadings for each element depending on which participants are included. These are then used to calculate bootstrap ratios (BSRs) by dividing the element loadings by the standard error of the distribution for each element. BSRs represent the stability of the spatial pattern showing the LV contrast, and are similar to z-scores in that absolute 
medRxiv preprint doi: https://doi.org/10.1101/2021.01.27.21250490; this version posted January 29, 2021. The copyright holder for this preprint (which was not certified by peer review) is the author/funder, who has granted medRxiv a license to display the preprint in perpetuity.

It is made available under a CC-BY-NC 4.0 International license .

BSR values $\geq 2$ correspond to a confidence interval of $\sim 95 \%$. We performed bootstrap resampling 1000 times per analysis. As the element loadings are all calculated in one mathematical step, no correction for multiple comparisons is necessary (i.e. patterns of connectivity across the whole brain are tested at once instead of individual connections).

First, we ran four PLS analyses comparing controls and all patients (grouped together), one for each ROI, to replicate previously found connectivity alterations in MDD. Next, we performed four PLS analyses including only patients, now grouped according to remission status (ER, LR, and NR), one for each of the four ROIs. For each significant LV, the spatial pattern was examined both manually and using the automated anatomical labeling (AAL) atlas [42] provided with the Fieldtrip toolbox [43]. Specifically, BSR thresholds were increased until the 10-15 clusters (involving 10 voxels or more) with the highest BSRs remained, and the areas in these clusters are reported in the results section. Manual inspection of these clusters was done using the MNI2TAL software developed by BioImage Suit and the Talairach atlas [44]. In addition, the voxels in these clusters were automatically labeled using the AAL atlas. Voxels that did not receive a label and regions with fewer than 3 voxels were not included. As we were primarily interested in group differences, we only report significant LVs that distinguished groups.

\section{Results}

\section{Participants}

There were no significant differences between patients and controls in the demographic characteristics presented in Table 1, except for controls having more years of education and a difference in the number of controls and patients tested at the different sites (Table 1). The three patient groups only differed in terms of their scores on the MADRS. By definition, early remitters had lower scores after 8 weeks of treatment, and both early and late remitters had lower scores after 16 weeks of treatment compared to non-remitters (Table 2). However, early remitters also showed lower MADRS scores at the start of 
medRxiv preprint doi: https://doi.org/10.1101/2021.01.27.21250490; this version posted January 29, 2021. The copyright holder for this preprint (which was not certified by peer review) is the author/funder, who has granted medRxiv a license to display the preprint in perpetuity. It is made available under a CC-BY-NC 4.0 International license .

treatment (Table 2). This baseline difference was beyond our control because group assignment was based on MADRS scores after 8 or 16 weeks of treatment.

\section{Replication of patient - control differences}

Anterior cingulate ROI. The PLS analysis comparing connectivity between the ACC ROI and the rest of the brain between patients with MDD and controls identified one significant LV $(p=.010$, percent crossblock covariance explained $(\mathrm{PCCE})=22.8 \%)$ that highlighted differences between patients and controls. In line with our expectations, the pattern of differences included stronger connectivity between the ACC ROI and DMN regions (vmPFC, left PCC \& left angular gyrus), the SN (right insula \& dorsal ACC) and parts of the $\mathrm{CCN}$ (dmPFC \& bilateral dlPFC) in patients compared to controls (see Figure 1A). In addition, this pattern included weaker connectivity between the ACC ROI and other parts of the CNN (bilateral PPC), the left extrastriate cortex and right premotor cortex, and stronger connectivity between the ACC ROI and the bilateral caudate nuclei, orbitofrontal cortex, left middle temporal gyrus and middle cingulate cortex in patients compared to controls. The labels of all the regions included in the 10-15 most stable clusters in this contrast, as determined by bootstrapping (BSR $\mid \geq 2.1$ ), were identified using the AAL, and are presented in Table S1.

Posterior cingulate ROI. The PLS analysis of connectivity between the PCC ROI and the rest of the brain in patients with MDD and controls did not identify significant LVs differentiating the two groups. However, one LV showing group differences in connectivity approached significance $(\mathrm{p}=.058$, PCCE $=21.7 \%$ ). As expected, this pattern included stronger connectivity between the PCC ROI and the precuneus (posterior DMN) and weaker connectivity between the PCC ROI and several CCN (bilateral dIPFC, right PPC) and SN (dorsal ACC) areas in patients compared to controls (see Figure 1B). In addition, this pattern included weaker connectivity between the PCC ROI and central motor areas (right SMA, bilateral premotor cortex), in patients compared to controls. The labels of all the regions included in the 10-15 most stable clusters, as determined by bootstrapping $(|\mathrm{BSR}| \geq 2.0)$, were identified using the AAL and are presented in Table $\mathbf{S 2}$. 
medRxiv preprint doi: https://doi.org/10.1101/2021.01.27.21250490; this version posted January 29, 2021. The copyright holder for this preprint (which was not certified by peer review) is the author/funder, who has granted medRxiv a license to display the preprint in perpetuity. It is made available under a CC-BY-NC 4.0 International license .

Insula ROI. The PLS analysis comparing patients with MDD and controls in connectivity between the insula ROI and the rest of the brain revealed one LV describing differences between patients and controls $(\mathrm{p}=.046, \mathrm{PCCE}=28.0 \%)$. As expected, the pattern of differences included weaker connectivity between the insula ROI and the PCC (posterior DMN) in patients compared to controls (see Figure 2A). Contrary to our expectations, we did not identify increased connectivity between the insula ROI and anterior DMN. In addition, the pattern included stronger connectivity between the insula ROI and the left $\mathrm{dlPFC}$ (from the $\mathrm{CCN}$ ), occipital/posterior temporal regions in patients compared to controls. The labels of all the regions included in the 10-15 most stable clusters, as determined by bootstrapping $(|\mathrm{BSR}| \geq 2.0)$, were identified using the AAL and are presented in Table S3.

Dorsolateral prefrontal cortex ROI. The PLS analysis of connectivity between the dlPFC ROI and the rest of the brain in patients and controls identified one LV revealing a pattern of group differences $(\mathrm{p}=.022, \mathrm{PCCE}=31.9 \%)$. In line with our expectations, this pattern included weaker connectivity between the dlPFC ROI and other CCN areas (right dlPFC, right PPC) in patients (see Figure 2B). At odds with our expectations, however, no connections between the dIPFC ROI and DMN regions were part of the pattern of differences. In addition, this pattern included stronger connectivity between the dlPFC ROI and SN regions (dorsal ACC \& bilateral insulae), and the left anterior PFC and weaker connectivity the dIPFC ROI and visual processing areas (left extrastriate cortex, left fusiform gyrus) in patients compared to controls. The labels of all the regions included in the 10-15 most stable clusters, as determined by bootstrapping $(|\mathrm{BSR}| \geq 2.0)$, were identified using the AAL and are presented in Table S4. 
medRxiv preprint doi: https://doi.org/10.1101/2021.01.27.21250490; this version posted January 29, 2021. The copyright holder for this preprint (which was not certified by peer review) is the author/funder, who has granted medRxiv a license to display the preprint in perpetuity. It is made available under a CC-BY-NC 4.0 International license .
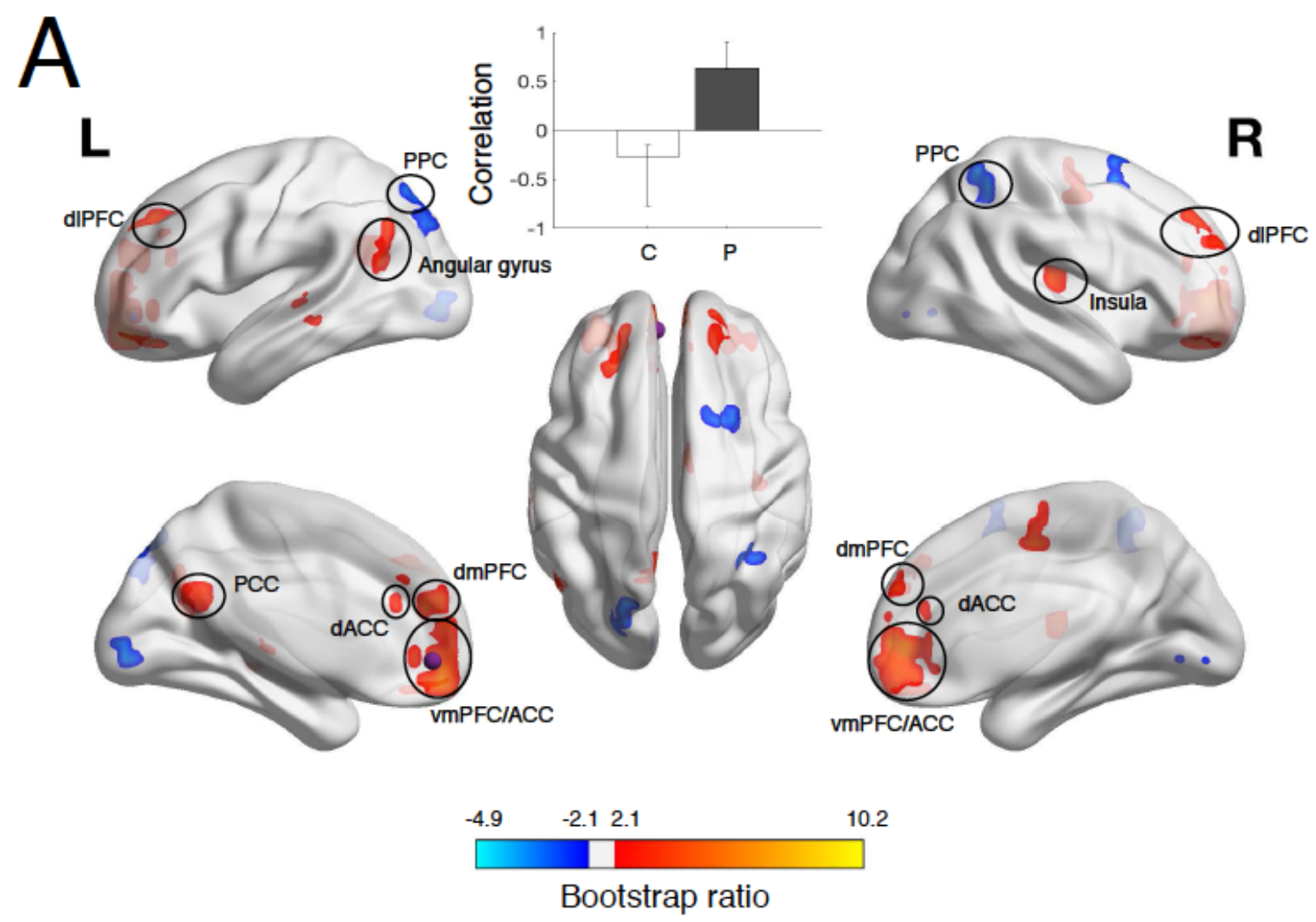

B
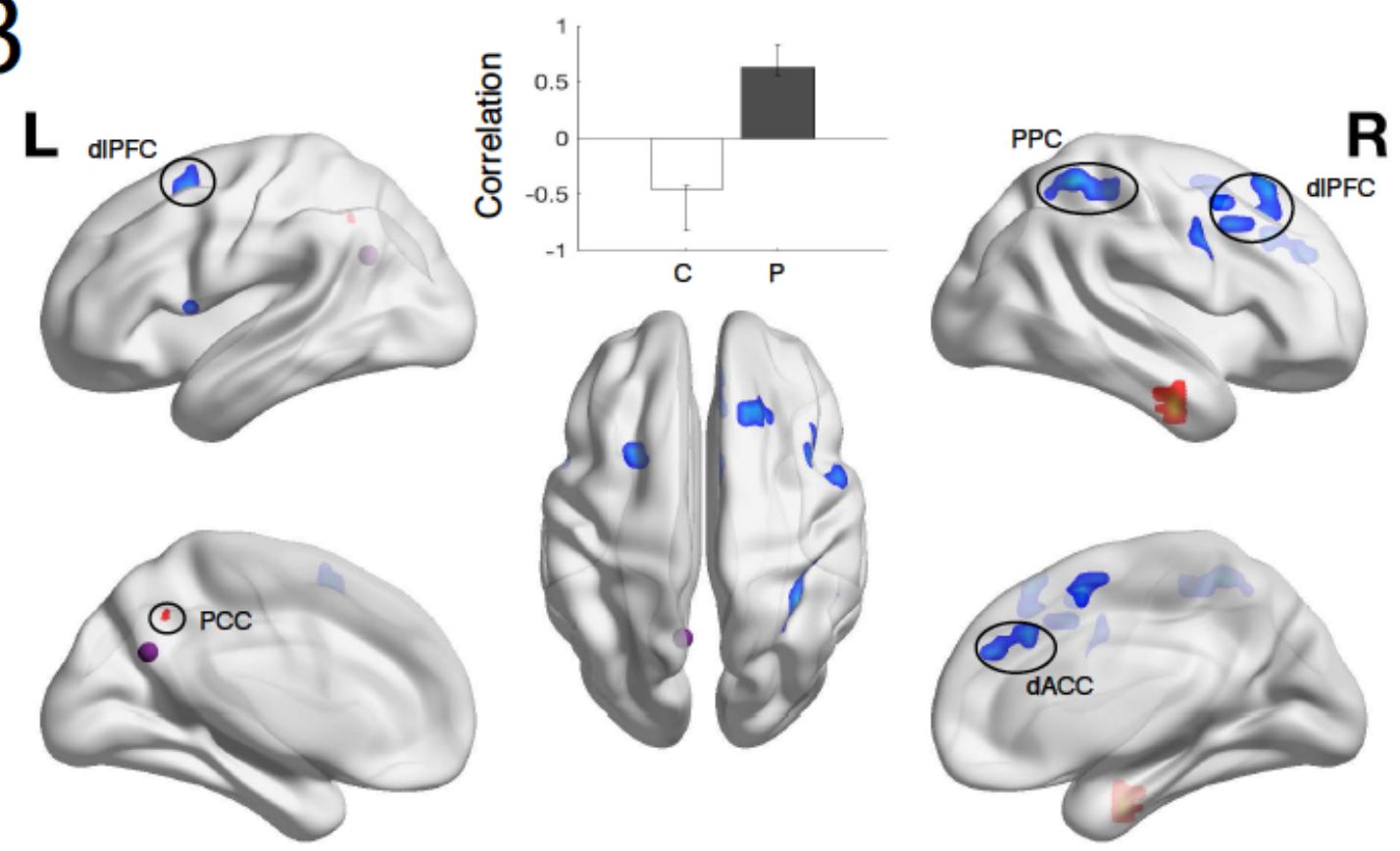

$-4.8$

$-22$

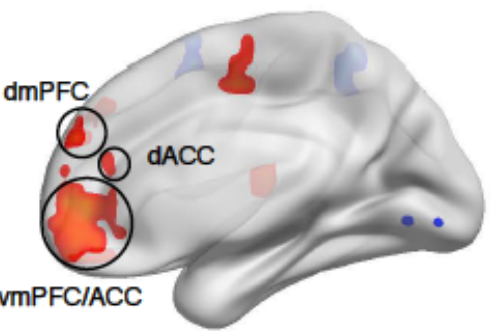

10.2

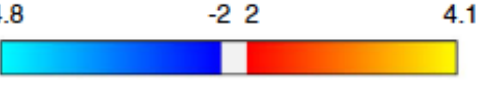

Bootstrap ratio 
medRxiv preprint doi: https://doi.org/10.1101/2021.01.27.21250490; this version posted January 29, 2021. The copyright holder for this preprint

(which was not certified by peer review) is the author/funder, who has granted medRxiv a license to display the preprint in perpetuity.

It is made available under a CC-BY-NC 4.0 International license .

Figure 1. Results from PLS analyses comparing patients with MDD and controls in terms of A)

connectivity between the ACC ROI (purple sphere) and all other voxels, and B) connectivity between the PCC ROI (purple sphere) and all other voxels, projected onto a smoothed cortical surface using BrainNet Viewer [45]. The correlation bar graph shows group-dependent differences in the correlation between the ROI voxels and the areas identified in the brain image. The error bars indicate the $95 \%$ confidence intervals derived from bootstrap estimation. The brain image illustrates the areas that expressed this contrast most stably across participants, as determined by bootstrapping. Only the $10-15$ clusters $(>10$ voxels) with the highest bootstrap ratios (ACC: $|\mathrm{BSR}| \geq 2.1$; PCC: $|\mathrm{BSR}| \geq 2.0$ ) are presented. Cerebellar clusters are not illustrated, but they are listed in table S1 (ACC) and table S2 (PCC). Red/yellow clusters indicate stronger, while blue clusters indicate weaker connectivity in patients as compared to controls. C $=$ controls, $\mathrm{P}=$ patients with major depressive disorder, $\mathrm{dlPFC}=$ dorsolateral prefrontal cortex, $\mathrm{PPC}=$ posterior parietal cortex $\mathrm{PCC}=$ posterior cingulate cortex $\mathrm{dACC}=$ dorsal anterior cingulate cortex, $\mathrm{dmPFC}=$ dorsomedial prefrontal cortex, $\mathrm{vmPFC}=$ ventromedial prefrontal cortex, $\mathrm{ACC}=$ anterior cingulate cortex. 
medRxiv preprint doi: https://doi.org/10.1101/2021.01.27.21250490; this version posted January 29, 2021. The copyright holder for this preprint (which was not certified by peer review) is the author/funder, who has granted medRxiv a license to display the preprint in perpetuity. It is made available under a CC-BY-NC 4.0 International license.

A
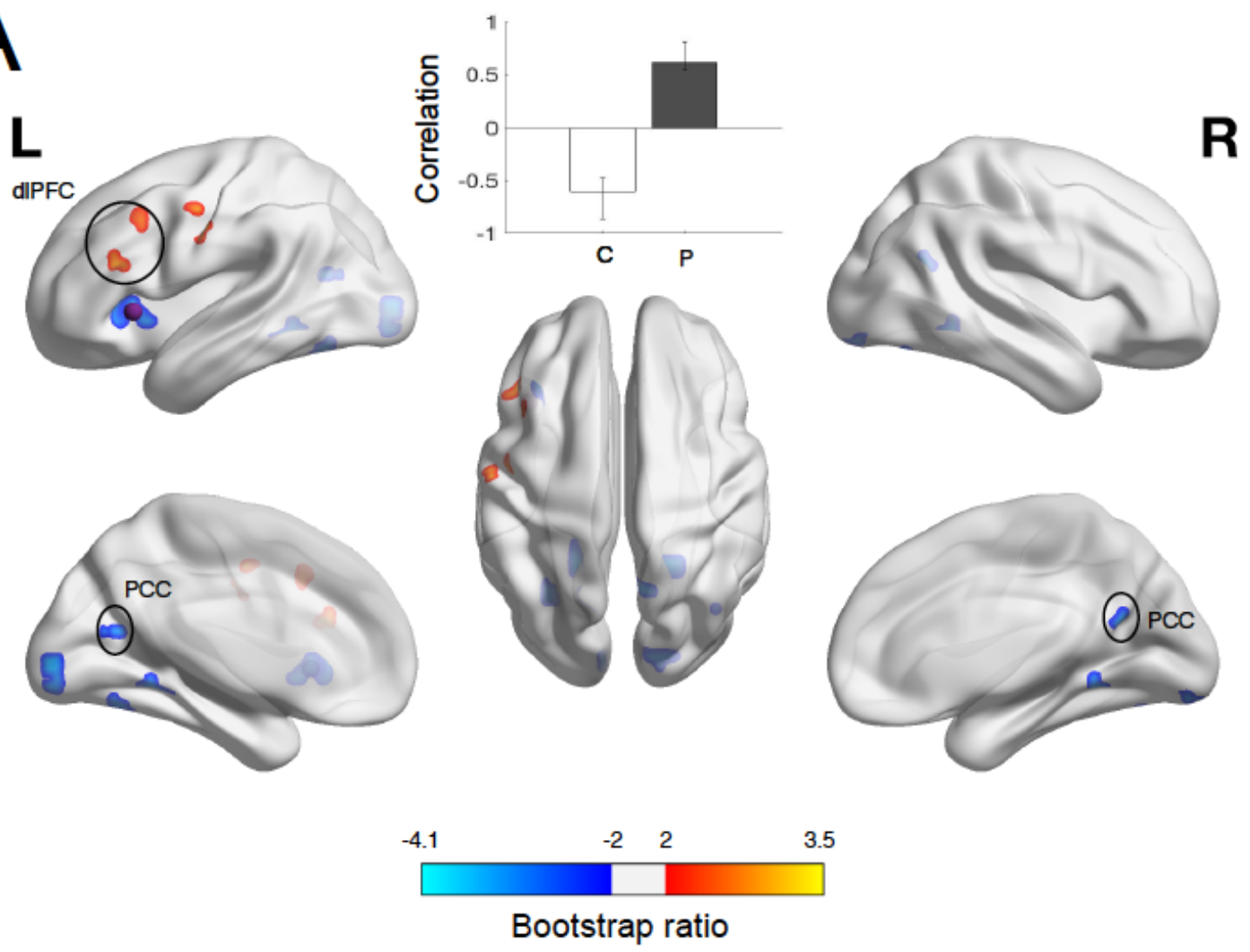

B
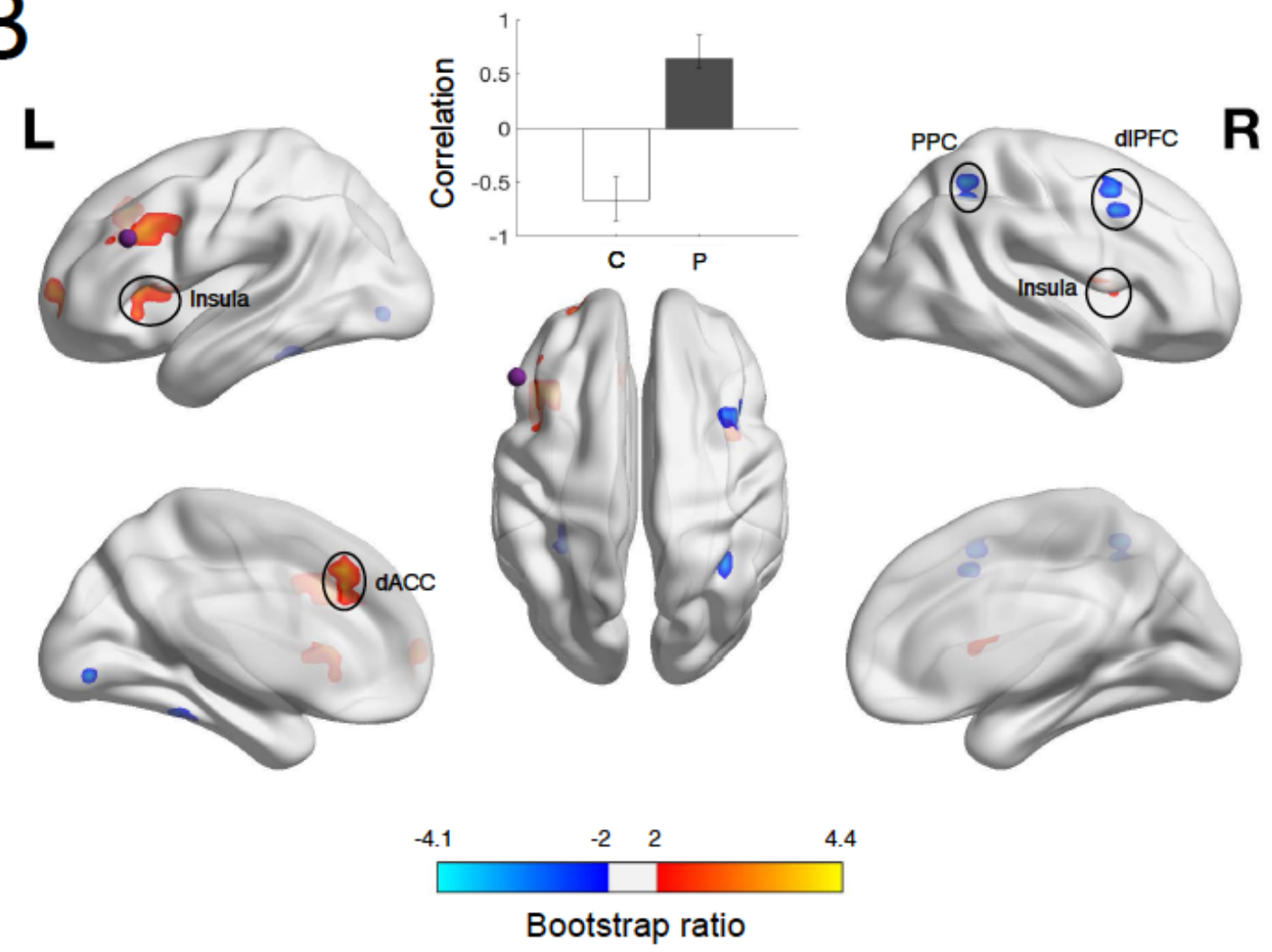
medRxiv preprint doi: https://doi.org/10.1101/2021.01.27.21250490; this version posted January 29, 2021. The copyright holder for this preprint (which was not certified by peer review) is the author/funder, who has granted medRxiv a license to display the preprint in perpetuity. It is made available under a CC-BY-NC 4.0 International license .

Figure 2. Results from PLS analyses comparing patients with MDD and controls in terms of A) connectivity between the insula ROI (purple sphere) and all other voxels, and B) connectivity between the dIPFC ROI (purple sphere) and all other voxels, projected onto a smoothed cortical surface using BrainNet Viewer [45]. The correlation bar graph shows group-dependent differences in the correlation between the ROI voxels and the areas identified in the brain image. The error bars indicate the $95 \%$ confidence intervals derived from bootstrap estimation. The brain image illustrates the areas that expressed this contrast most stably across participants, as determined by bootstrapping. Only the 10-15 clusters ( $>10$ voxels) with the highest bootstrap ratios (insula: $|\mathrm{BSR}| \geq 2.0$; dlPFC: $|\mathrm{BSR}| \geq 2.0$ ) are presented. Cerebellar clusters are not illustrated, but they are listed in table S3 (insula) and table S4 (dlPFC). Red/yellow clusters indicate stronger, while blue clusters indicate weaker connectivity in patients compared to controls. $\mathrm{C}=$ controls, $\mathrm{P}=$ patients with major depressive disorder, $\mathrm{dlPFC}=$ dorsolateral prefrontal cortex, $\mathrm{PPC}=$ posterior parietal cortex, $\mathrm{PCC}=$ posterior cingulate cortex, $\mathrm{dACC}=$ dorsal anterior cingulate cortex.

\section{Early, late and non-remitter comparison - anterior cingulate seed}

The PLS analysis examining connectivity between the ACC ROI and all voxels in the brain across the patient groups (ER, LR, and NR) identified one significant LV $(p=.008, \operatorname{PCCE}=31.4 \%)$ that differentiated between early remitters and the other two groups (see bar graph in Figure 3). This group specific contrast included stronger connectivity between the ACC ROI and the cerebellum, the PCC and the right occipital cortex (BA18), and weaker connectivity between the ACC ROI and the bilateral dlPFC, the medial anterior PFC, right subgenual ACC, right caudate nucleus, right superior temporal gyrus, left insula and the right extrastriate cortex (BA19) in early remitters compared to the other two groups (see Figure 3). The labels of all the regions included in the 10-15 clusters showing the most stable group differences, as determined by bootstrapping $(|\mathrm{BSR}| \geq 2.4)$, were determined using the AAL atlas and are presented in Table 3. 


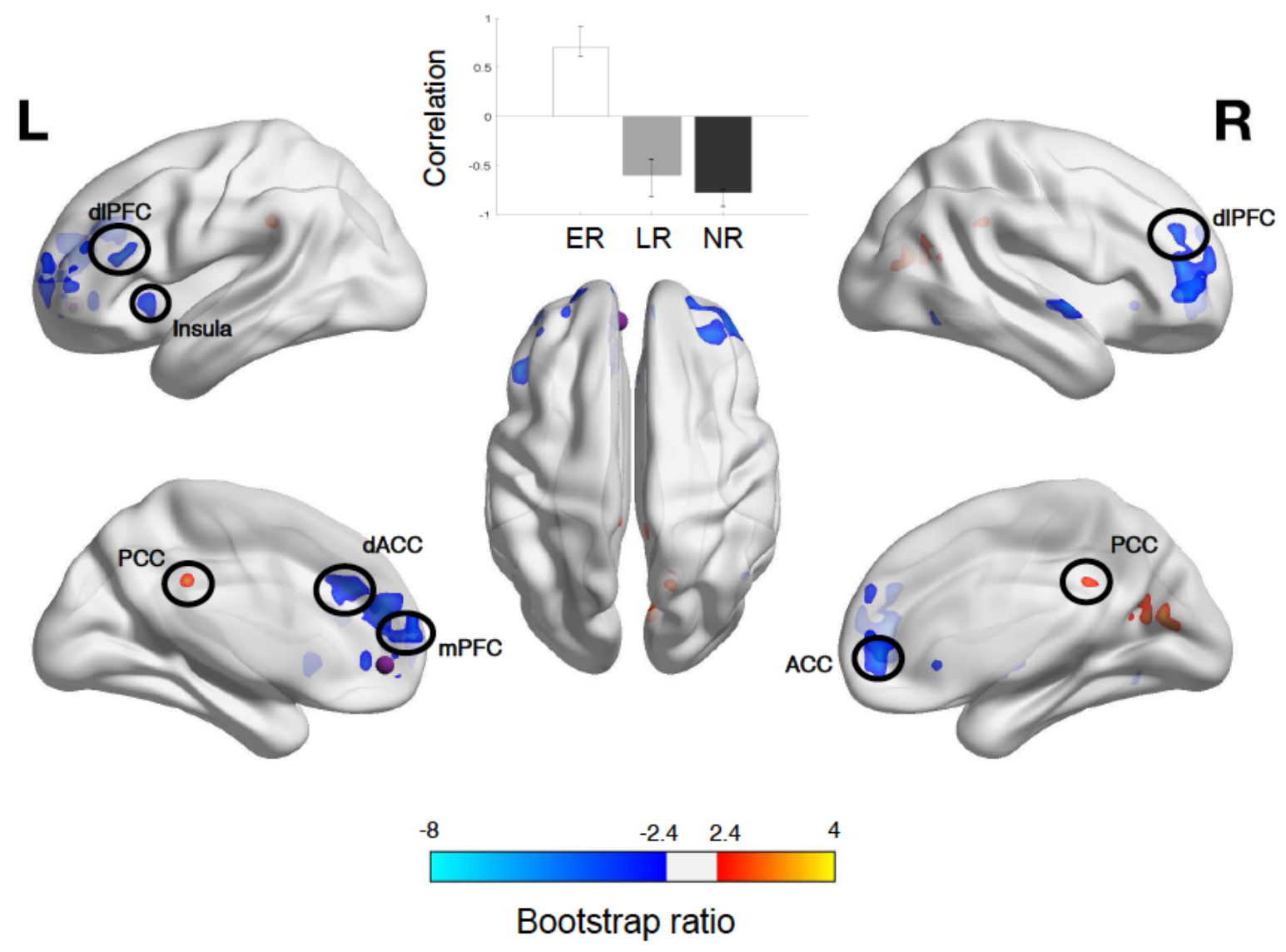

Figure 3. Results from PLS analysis comparing early, late and non-remitters in terms of connectivity between the ACC ROI (purple sphere) and all other voxels, projected onto a smoothed cortical surface using BrainNet Viewer [45]. The correlation bar graph shows group-dependent differences in the correlation between the ROI voxels and the areas identified in the brain image. The error bars indicate the $95 \%$ confidence intervals derived from bootstrap estimation. The brain image illustrates the areas that expressed this contrast most stably across participants, as determined by bootstrapping. Only the 10-15 clusters $(>10$ voxels $)$ with the highest bootstrap ratios $(|\mathrm{BSR}| \geq 2.4)$ are presented. Cerebellar clusters are not illustrated, but they are listed in table 3. Red/yellow clusters indicate stronger, while blue clusters indicate weaker connectivity in early compared to late and non-remitters. $\mathrm{ER}=$ early remitters, $\mathrm{LR}=$ late remitters, $\mathrm{NR}=$ non-remitters, $\mathrm{dlPFC}=$ dorsolateral prefrontal cortex, $\mathrm{PCC}=$ posterior cingulate cortex, $\mathrm{dACC}=$ dorsal anterior cingulate cortex $\mathrm{mPFC}=$ medial prefrontal cortex, $\mathrm{ACC}=$ anterior cingulate cortex. 
medRxiv preprint doi: https://doi.org/10.1101/2021.01.27.21250490; this version posted January 29, 2021. The copyright holder for this preprint (which was not certified by peer review) is the author/funder, who has granted medRxiv a license to display the preprint in perpetuity.

It is made available under a CC-BY-NC 4.0 International license.

Table 3. Regions Showing Distinct Connectivity with the Anterior Cingulate Cortex in Early, Late and Non-remitters Automatically Labeled Using the AAL Atlas

Peak MNI

Cluster

Number Peak

coordinates

Contrast Cluster size

Area

of voxels BSR $x$

y $\quad \mathbf{z}$

LV1: ER

$>$ LR \&

NR

\begin{tabular}{cccccccc}
1 & 18 & L crus II of cerebellar hemisphere & 16 & 3.94 & -40 & -72 & -40 \\
\hline 2 & 10 & R lingual gyrus & 3 & 3.36 & 12 & -48 & 0 \\
& & & & & & \\
& R lobule IV, V of cerebellar & & & & \\
& hemisphere & 3 & 3.86 & 8 & -48 & 0 \\
& & Lobule IV, V of vermis & 3 & 3.37 & 0 & -52 & 0 \\
\hline 3 & 10 & R median cingulate/paracingulate gyri & 3 & 3.05 & 4 & -40 & 32 \\
& & L posterior cingulate gyrus & 5 & 3.51 & -4 & -36 & 32 \\
\hline 4 & 16 & R calcarine fissure & 10 & 3.50 & 16 & -64 & 16 \\
& & R Cuneus & 3 & 2.63 & 16 & -64 & 20 \\
\hline
\end{tabular}

LV1: ER

$<$ LR \&

NR

$5 \quad 153$

L medial superior frontal gyrus

49

$\mathrm{R}$ medial superior frontal gyrus

25

$\begin{array}{llll}-5.10 & -12 & 44 & 24\end{array}$

L medial superior frontal gyrus, orbital

$$
\text { part }
$$

$\begin{array}{llll}-5.68 & 0 & 48 & -8\end{array}$

$\mathrm{R}$ medial superior frontal gyrus, orbital

$\begin{array}{llllll}\text { part } & 12 & -7.94 & 4 & 48 & -4\end{array}$

$\begin{array}{lllllll}\mathrm{L} \text { anterior cingulate/paracingulate gyri } & 43 & -4.41 & 0 & 48 & 0\end{array}$

$\begin{array}{lllllll}\mathrm{R} \text { anterior cingulate/paracingulate gyri } & 8 & -4.15 & 4 & 52 & 8\end{array}$

\begin{tabular}{cccccccc}
\hline 6 & 13 & L inferior frontal gyrus, triangular part & 13 & -5.18 & -48 & 28 & 16 \\
\hline 7 & 65 & R dorsolateral superior frontal gyrus & 12 & -3.73 & 24 & 56 & 16 \\
& & R middle frontal gyrus & 41 & -5.14 & 40 & 44 & 12 \\
& & R inferior frontal gyrus, triangular part & 10 & -4.77 & 48 & 40 & 12 \\
\hline 8 & 33 & L dorsolateral superior frontal gyrus & 17 & -4.94 & -24 & 64 & 0 \\
& & L middle frontal gyrus & 12 & -4.40 & -28 & 48 & 8 \\
\hline
\end{tabular}




\begin{tabular}{cccccccc}
\hline 10 & 22 & R middle frontal gyrus & 22 & -4.77 & 36 & 44 & 28 \\
\hline 11 & 15 & R superior temporal gyrus & 13 & -4.33 & 56 & -4 & -4 \\
\hline 12 & 11 & L insula & 9 & -3.63 & -36 & 16 & -4 \\
\hline 13 & 11 & R middle temporal gyrus & 3 & -3.08 & 40 & -64 & 4 \\
& & R inferior temporal gyrus & 3 & -3.02 & 44 & -64 & -4 \\
\hline 14 & 17 & L middle frontal gyrus & 16 & -3.31 & -40 & 52 & 4 \\
\hline
\end{tabular}

Note. Only the regions included in the 10-15 most stable clusters per LV are presented in this table

( $\mid$ Bootstrap Ratios $\mid \geq 2.4$, Cluster Size $\geq 10) . E R=$ early remitter, $\mathrm{LR}=$ late remitter, NR = non-remitter, $\mathrm{BSR}=$ bootstrap ratio, $\mathrm{R}=$ right, $\mathrm{L}=$ left.

\section{Early, late and non-remitter comparison-posterior cingulate seed}

The result of the PLS analysis investigating connectivity between the PCC ROI and all voxels in the brain identified one significant LV $(\mathrm{p}=.016, \mathrm{PCCE}=24.7 \%)$ which distinguished the three groups. Early and late remitters showed a pattern of connectivity that was most consistently expressed as stronger connectivity between the PCC ROI and the precuneus/right PCC, the cerebellum, the bilateral superior temporal gyrus, orbital PFC, dorsal and pregenual ACC and the left fusiform gyrus, and weaker connectivity between the PCC ROI and the right superior temporal gyrus compared to non-remitters. Importantly, early remitters exhibited this pattern of connectivity more strongly than late remitters (see bar graph in Figure 4). All regions identified in the 10-15 most stable clusters, as determined by bootstrapping $(|\mathrm{BSR}|>2.3)$, were labeled using the AAL atlas and are listed in Table 4. 


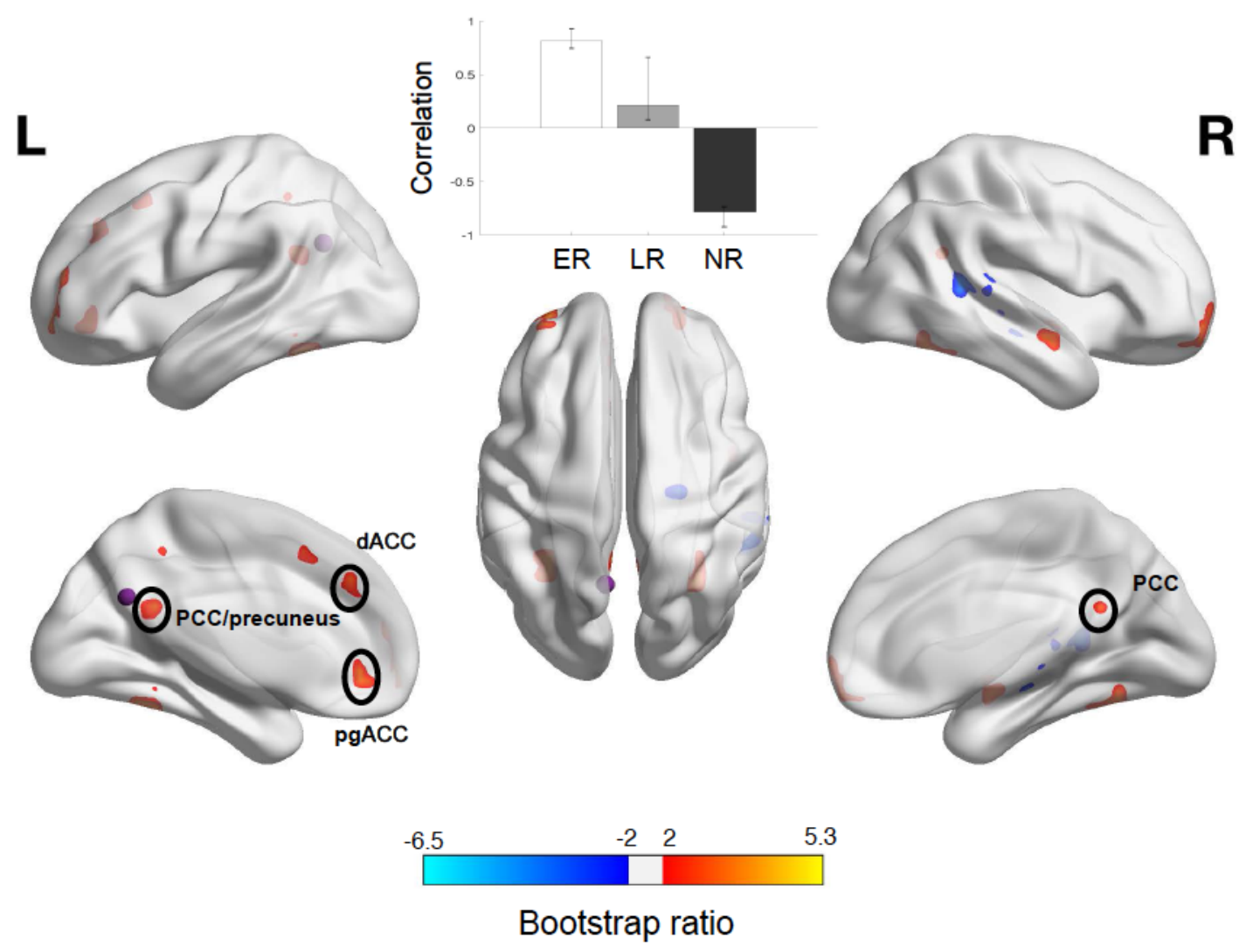

Figure 4. Results from PLS analysis comparing early, late and non-remitters in terms of connectivity between the PCC ROI (purple sphere) and all other voxels, projected onto a smoothed cortical surface using BrainNet Viewer [45]. The correlation bar graph shows group-dependent differences in the correlation between the ROI voxels and the areas identified in the brain image. The error bars indicate the $95 \%$ confidence intervals derived from bootstrap estimation. The brain image illustrates the areas that expressed this contrast most stably across participants, as determined by bootstrapping. Only the 10-15 clusters $(>10$ voxels $)$ with the highest bootstrap ratios $(|\mathrm{BSR}| \geq 2.4)$ are presented. Cerebellar clusters are not illustrated, but they are listed in table 4. Red/yellow clusters indicate stronger, while blue clusters indicate weaker connectivity in early remitters compared to late and non-remitters, as well as in late compared to non-remitters. $\mathrm{ER}=$ early remitters, $\mathrm{LR}=$ late remitters, $\mathrm{NR}=$ non-remitters, $\mathrm{PCC}=$ posterior cingulate cortex, $\mathrm{dACC}=$ dorsal anterior cingulate cortex, $\mathrm{pgACC}=$ pregenual anterior cingulate cortex. 
medRxiv preprint doi: https://doi.org/10.1101/2021.01.27.21250490; this version posted January 29, 2021. The copyright holder for this preprint (which was not certified by peer review) is the author/funder, who has granted medRxiv a license to display the preprint in perpetuity.

It is made available under a CC-BY-NC 4.0 International license .

Table 4. Regions Showing Distinct Connectivity with the Posterior Cingulate Cortex in Early, Late and Non-remitters Automatically Labeled Using the AAL Atlas

\section{Cluster}

\section{Contrast Cluster size Area}

Number Peak $\begin{array}{llllll}\text { of voxels } & \text { BSR } & \mathbf{x} & \mathbf{y} & \mathbf{z}\end{array}$

coordinates

LV1: ER
$<$ LR <
NR

NR

1

15 R superior temporal gyrus

$\mathrm{R}$ middle temporal gyrus
33 R fusiform gyrus

$\mathrm{R}$ crus I of cerebellar hemisphere

$\mathrm{R}$ lobule VI of cerebellar hemisphere

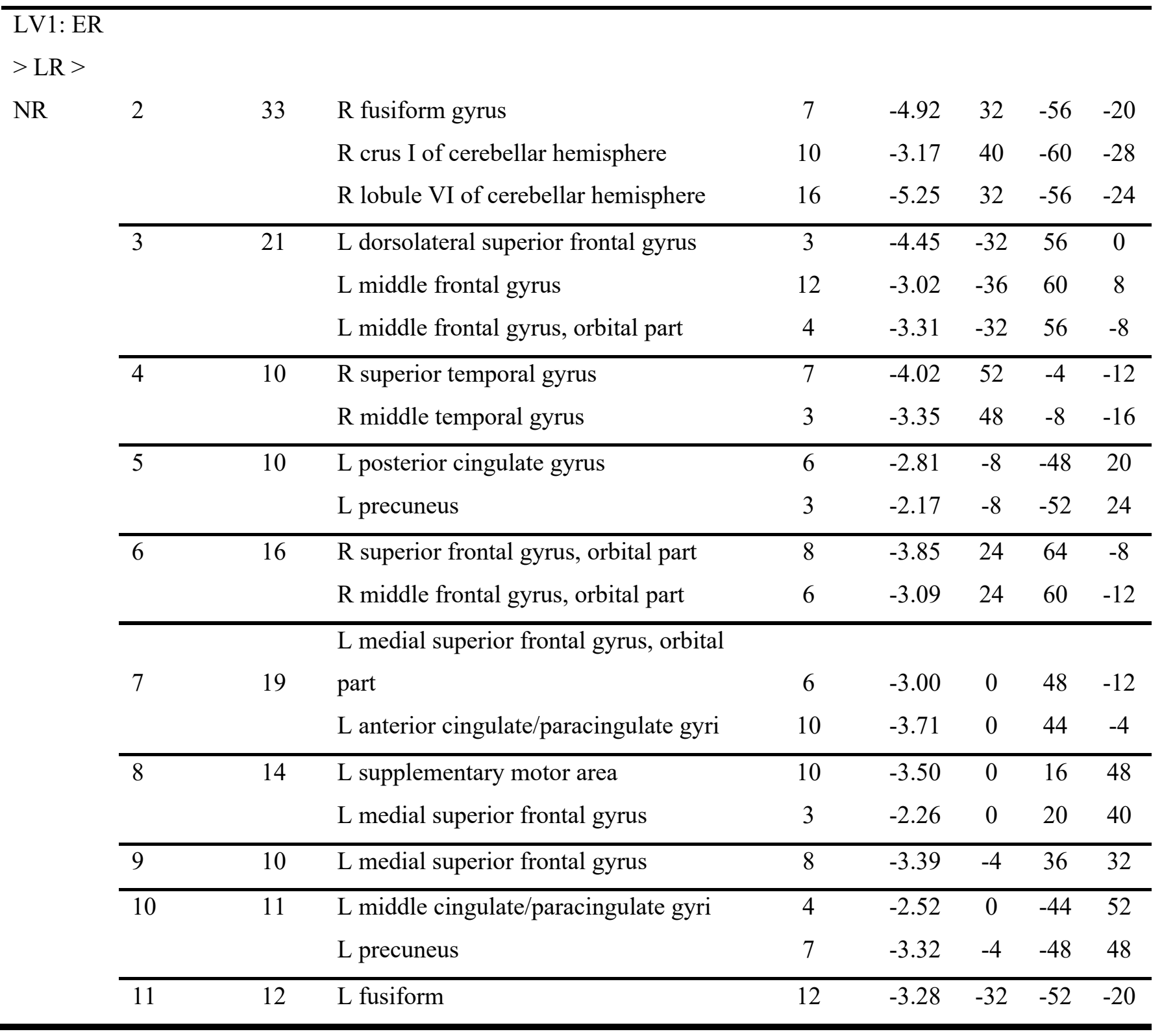

L middle frontal gyrus, orbital part

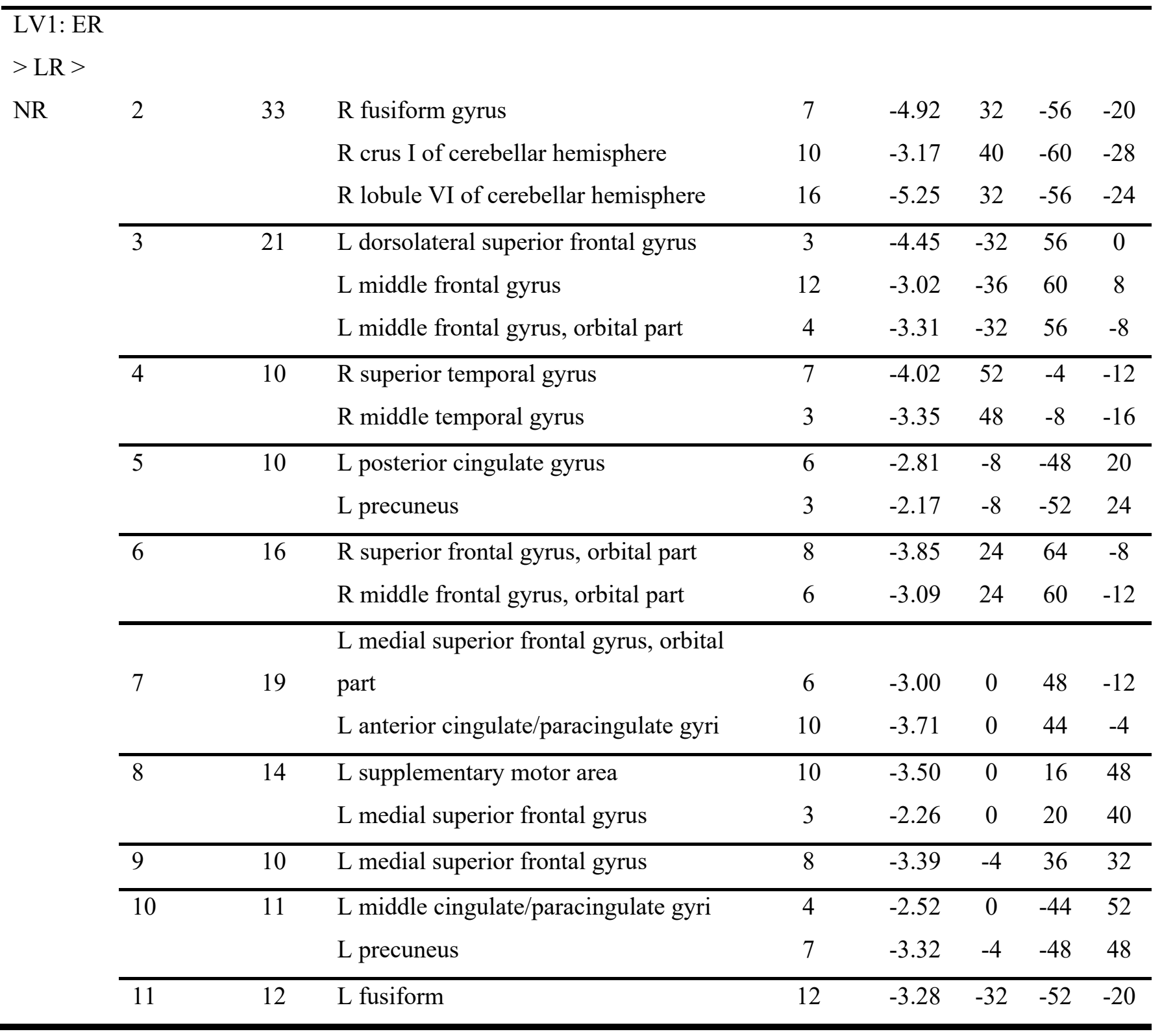

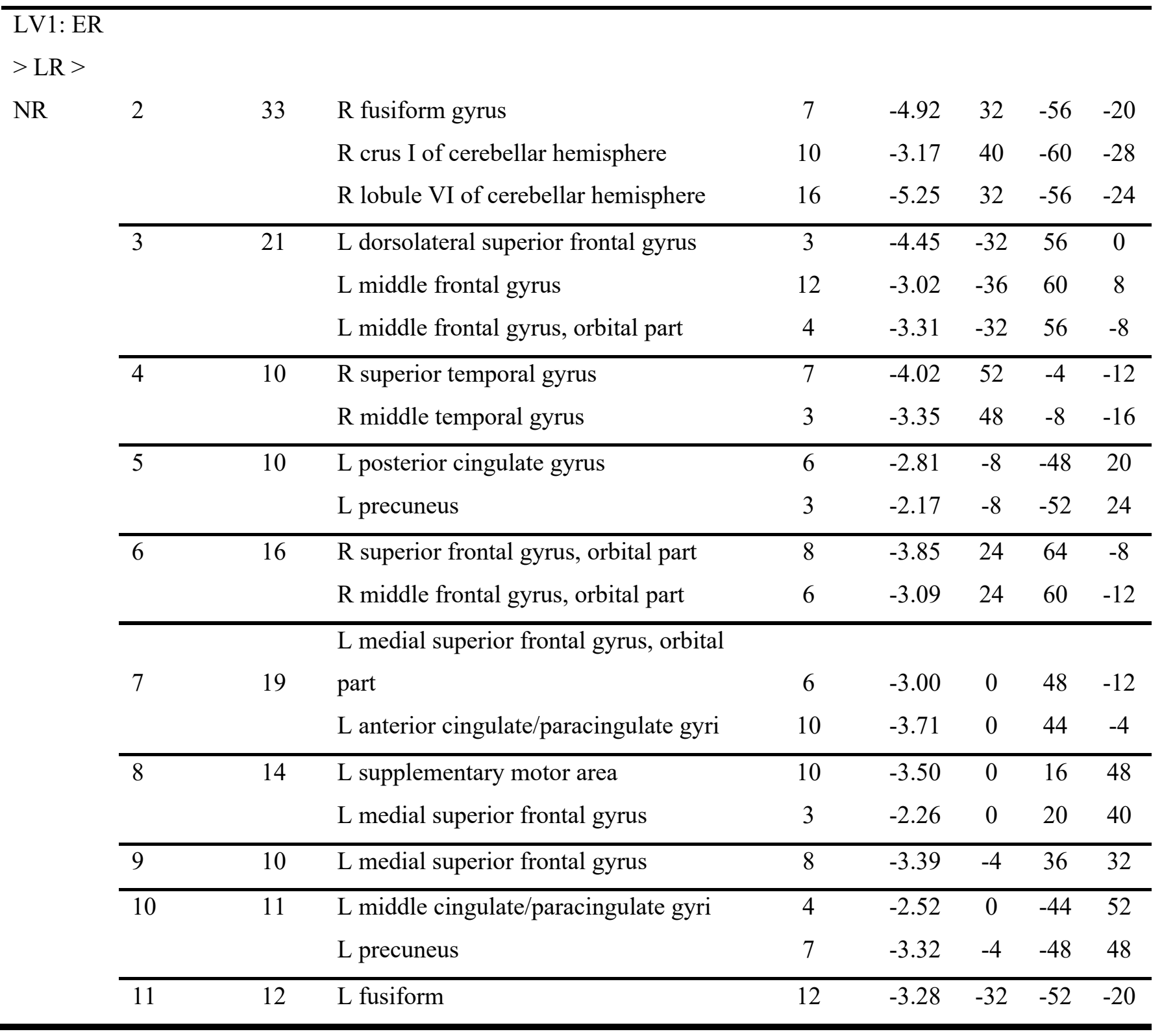

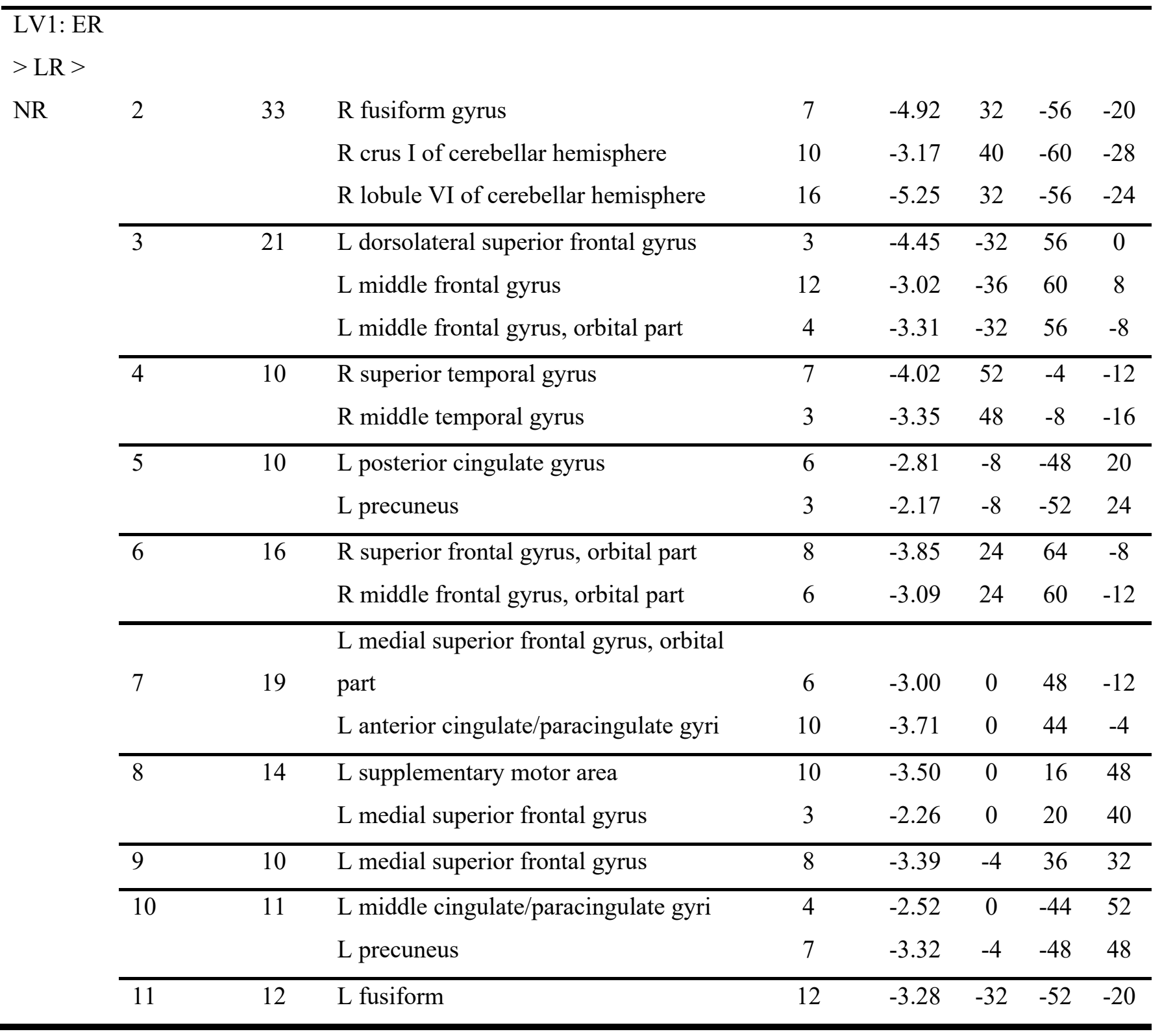

$\mathrm{R}$ middle frontal gyrus, orbital part

$$
7
$$

$7 \quad 19$ part

L anterior cingulate/paracingulate gyri

$$
8
$$

8

9

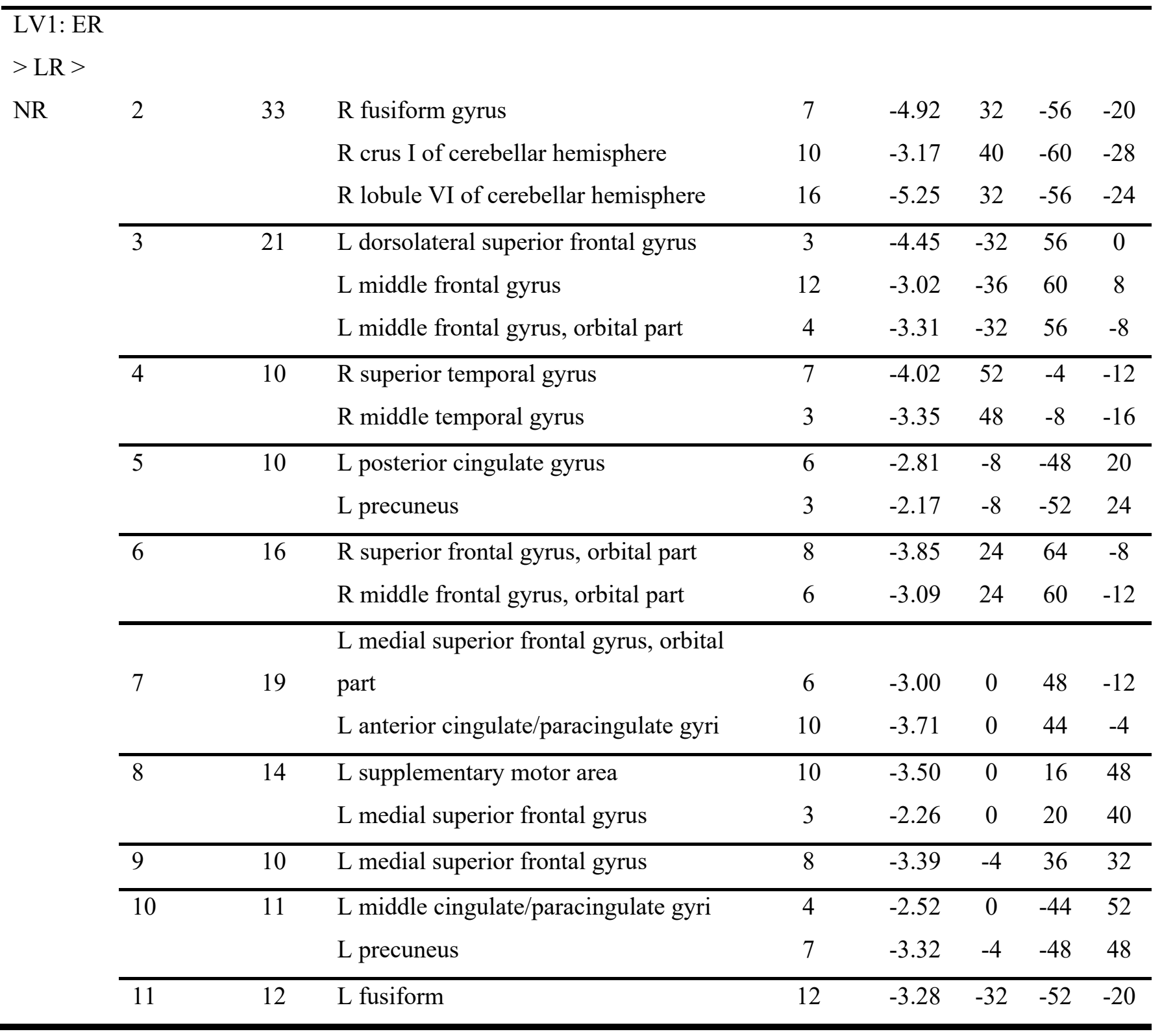

11

12 L fusiform

L supplementary motor area

12

3.49

$\begin{array}{lll}52 & -44 & 12\end{array}$

3

4.27

$52-44$

Peak MNI 
medRxiv preprint doi: https://doi.org/10.1101/2021.01.27.21250490; this version posted January 29, 2021. The copyright holder for this preprint

(which was not certified by peer review) is the author/funder, who has granted medRxiv a license to display the preprint in perpetuity.

It is made available under a CC-BY-NC 4.0 International license .

Note. Only the regions included in the 10-15 most stable clusters per LV are presented in this table

$(\mid$ Bootstrap Ratios $\mid \geq 2.0$, Cluster Size $\geq 10) . E R=$ early remitter, $\mathrm{LR}=$ late remitter, NR = non-remitter, $\mathrm{BSR}=$ bootstrap ratio, $\mathrm{R}=$ right, $\mathrm{L}=$ left.

\section{Early, late and non-remitter comparison - insula ROI}

The PLS analysis of connectivity between the insula ROI and the rest of the brain in early, late and nonremitters identified two significant LVs (LV1: $p=.005 ; \mathrm{PCCE}=27.8 \%, \mathrm{LV} 2: \mathrm{p}=.044, \mathrm{PCCE}=23.1 \%)$ differentiating between patient groups. The first differentiated late and early remitters, with early remitters showing stronger connectivity between the insula ROI and the PCC/precuneus, bilateral fusiform gyrus, PPC, anterior and medial PFC, ACC, the left FEF, the left dlPFC and the right angular gyrus, and weaker connectivity between the insula ROI and the right insula, right inferior frontal gyrus, the cerebellum and the left putamen, as compared to late remitters (see Figure 5). All regions identified in the 10-15 most stable clusters, as determined by bootstrapping ( $|\mathrm{BSR}| \geq 2.4)$, were labeled using the AAL atlas and are listed in Table $\mathbf{5}$.

The second LV distinguished between remitters and non-remitters. Specifically, non-remitters showed stronger connectivity between the insula ROI and the cerebellum, right extrastriate cortex and right operculum, and weaker connectivity between the insula ROI and the cerebellum, right insula, left angular gyrus, putamen, $\mathrm{mPFC}$ and parahippocampal gyrus compared to both early and late remitters. All regions identified in the 10-15 most stable clusters, as determined by bootstrapping $(|\mathrm{BSR}| \geq 2.1)$, were labeled using the AAL atlas and are listed in Table 5. 

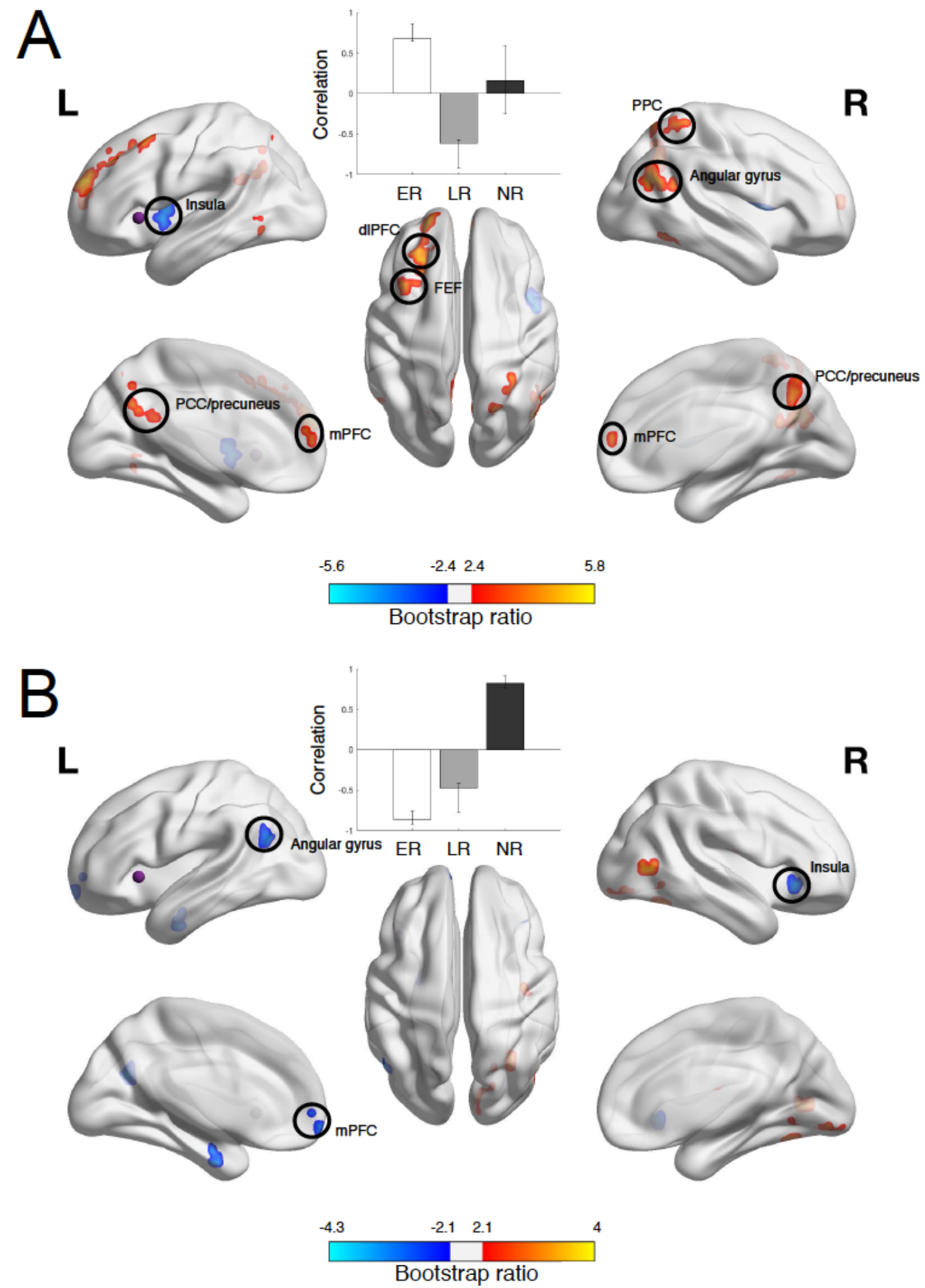

Figure 5. Results from PLS analysis comparing early, late and non-remitters in terms of connectivity between the insula ROI (purple sphere) and all other voxels, projected onto a smoothed cortical surface 
medRxiv preprint doi: https://doi.org/10.1101/2021.01.27.21250490; this version posted January 29, 2021. The copyright holder for this preprint (which was not certified by peer review) is the author/funder, who has granted medRxiv a license to display the preprint in perpetuity.

It is made available under a CC-BY-NC 4.0 International license .

using BrainNet Viewer [45]. A) shows the contrast and spatial pattern identified in the first LV, B)

contrast and spatial pattern identified for the second LV. The correlation bar graph shows group-

dependent differences in the correlation between the ROI voxels and the areas identified in the brain

image. The error bars indicate the $95 \%$ confidence intervals derived from bootstrap estimation. The brain

image illustrates the areas that expressed this contrast most stably across participants, as determined by

bootstrapping. Only the $10-15$ clusters ( $>10$ voxels) with the highest bootstrap ratios $(|\mathrm{BSR}| \geq 2.4)$ are

presented. Cerebellar clusters are not illustrated, but they are listed in table 5. In A) red/yellow clusters

indicate stronger, while blue clusters indicate weaker connectivity in early remitters compared to late

remitters. In B) red/yellow clusters indicate stronger, while blue clusters indicate weaker connectivity in

non-remitters compared to early and late remitters. $E R=$ early remitters, $L R=$ late remitters, $N R=$ non-

remitters, $\mathrm{dlPFC}=$ dorsolateral prefrontal cortex, $\mathrm{PPC}=$ posterior parietal cortex, $\mathrm{FEF}=$ frontal eye fields,

$\mathrm{PCC}=$ posterior cingulate cortex $\mathrm{mPFC}=$ medial prefrontal cortex, $\mathrm{LV}=$ latent variable

Table 5. Regions Showing Distinct Connectivity with the Insula in Early, Late and Non-remitters, Automatically Labeled Using the AAL Atlas

\section{Cluster}

Contrast Cluster

LV1: ER size Area

$>$ LR
22 L dorsolateral superior frontal gyrus

L middle frontal gyrus

\begin{tabular}{cclccccc}
1 & 22 & L dorsolateral superior frontal gyrus & 14 & 5.75 & -24 & 56 & 24 \\
& & L middle frontal gyrus & 8 & 4.45 & -24 & 52 & 24 \\
\hline 2 & 14 & L middle frontal gyrus & 14 & 5.32 & -44 & 20 & 48 \\
\hline 3 & 31 & L dorsolateral superior frontal gyrus & 12 & 5.04 & -28 & 40 & 40 \\
& & L middle frontal gyrus & 19 & 4.85 & -28 & 32 & 40 \\
\hline 4 & 40 & R middle occipital gyrus & 9 & 4.01 & 44 & -68 & 24 \\
& & R angular gyrus & 13 & 4.94 & 44 & -56 & 24 \\
& & R middle temporal gyrus & 17 & 4.31 & 44 & -56 & 20 \\
\hline 5 & 21 & R postcentral gyrus & 5 & 4.19 & 32 & -44 & 60 \\
& & R superior parietal gyrus & 15 & 4.72 & 32 & -48 & 60 \\
\hline
\end{tabular}

Peak MNI

Number Peak coordinates

$\begin{array}{lllll}\text { of voxels } & \text { BSR } & \mathbf{x} & \mathbf{y} & \mathbf{z}\end{array}$

B




\begin{tabular}{cclccccc}
\hline 6 & 13 & L middle temporal gyrus & 5 & 4.47 & -56 & -64 & -4 \\
& & L inferior temporal gyrus & 7 & 3.59 & -56 & -64 & -8 \\
\hline 7 & 10 & R inferior frontal gyrus, orbital part & 4 & 3.03 & 40 & 24 & -20 \\
& & & & & & \\
& & R temporal pole: superior temporal & & & & \\
& & gyrus & 6 & 4.12 & 44 & 24 & -20 \\
\hline 8 & 54 & L posterior cingulate gyrus & 7 & 3.04 & -4 & -52 & 28 \\
& & L superior parietal gyrus & 11 & 3.96 & -16 & -64 & 40 \\
& & L precuneus & 19 & 4.08 & -8 & -60 & 32 \\
& & R precuneus & 15 & 3.92 & 8 & -60 & 36 \\
\hline 9 & 12 & R inferior temporal gyrus & 12 & 4.05 & 48 & -60 & -12 \\
\hline 10 & 10 & R superior parietal gyrus & 10 & 3.96 & 20 & -64 & 56 \\
\hline 11 & 25 & L medial superior frontal gyrus & 11 & 3.18 & -8 & 52 & 16 \\
& & R medial superior frontal gyrus & 4 & 3.61 & 8 & 56 & 12 \\
& & L anterior cingulate/paracingulate gyri & 9 & 3.28 & 0 & 44 & 8 \\
\hline
\end{tabular}

LV1: ER

$<\mathrm{LR}$

$12 \quad 11 \quad \mathrm{R}$ inferior frontal gyrus, opercular part

$\begin{array}{lllll}3 & -5.05 & 44 & 8 & 8\end{array}$

$\mathrm{R}$ rolandic operculum

$\begin{array}{lllll}4 & -5.58 & 48 & 0 & 8\end{array}$

$\mathrm{R}$ insula

4

13

$13 \quad 24$

L insula

L putamen

12
7

$\mathrm{R}$ lobule IV, $\mathrm{V}$ of cerebellar

$14 \quad 15$ hemisphere

Lobule IV, V of vermis

$\begin{array}{lllll}5 & -2.97 & 8 & -56 & -12 \\ 8 & -3.97 & 0 & -52 & -12\end{array}$

LV2: ER

$\& \mathrm{LR}<$

\begin{tabular}{|c|c|c|c|c|c|c|c|c|}
\hline \multirow{3}{*}{\multicolumn{2}{|c|}{ NR }} & \multirow[t]{3}{*}{18} & $\mathrm{R}$ lingual gyrus & 4 & 2.99 & 20 & -60 & -4 \\
\hline & & & $\mathrm{R}$ fusiform gyrus & 8 & 3.57 & 32 & -56 & -20 \\
\hline & & & R lobule VI of cerebellar hemisphere & 6 & 3.98 & 32 & -60 & -24 \\
\hline & 2 & 11 & $\mathrm{R}$ rolandic operculum & 6 & 3.94 & 40 & -12 & 20 \\
\hline & 3 & 10 & $\mathrm{R}$ lingual gyrus & 10 & 3.20 & 12 & -88 & -8 \\
\hline & 4 & 14 & $\mathrm{R}$ middle temporal gyrus & 11 & 3.09 & 44 & -68 & 4 \\
\hline
\end{tabular}




\begin{tabular}{|c|c|c|c|c|c|c|c|c|}
\hline \multicolumn{9}{|c|}{ LV2: ER } \\
\hline$\&$ L & & & & & & & & \\
\hline \multirow[t]{14}{*}{ NR } & \multirow[t]{3}{*}{5} & \multirow[t]{3}{*}{18} & L medial superior frontal gyrus & 8 & -4.33 & 0 & 60 & 4 \\
\hline & & & L medial superior frontal gyrus, orbital & & & & & \\
\hline & & & part & 7 & -3.15 & -4 & 64 & -8 \\
\hline & \multirow[t]{2}{*}{6} & \multirow[t]{2}{*}{19} & $\mathrm{R}$ crus I of cerebellar hemisphere & 8 & -3.20 & 16 & -76 & -32 \\
\hline & & & $\mathrm{R}$ crus II of cerebellar hemisphere & 8 & -3.99 & 20 & -80 & -40 \\
\hline & 7 & 10 & $\mathrm{R}$ crus I of cerebellar hemisphere & 7 & -3.82 & 28 & -64 & -40 \\
\hline & 8 & 11 & L lobule VIII of cerebellar hemisphere & 6 & -3.45 & -24 & -60 & -40 \\
\hline & \multirow[t]{2}{*}{9} & \multirow[t]{2}{*}{13} & $\mathrm{R}$ inferior frontal gyrus, orbital part & 6 & -2.92 & 40 & 24 & -8 \\
\hline & & & $\mathrm{R}$ insula & 5 & -3.43 & 36 & 24 & -4 \\
\hline & 10 & 11 & L putamen & 7 & -3.11 & -28 & 8 & -4 \\
\hline & \multirow[t]{2}{*}{11} & \multirow[t]{2}{*}{14} & $\mathrm{~L}$ angular gyrus & 9 & -3.00 & -52 & -68 & 24 \\
\hline & & & L middle temporal gyrus & 5 & -2.88 & -52 & -68 & 20 \\
\hline & \multirow[t]{2}{*}{12} & \multirow[t]{2}{*}{11} & L hippocampus & 3 & -2.75 & -32 & -8 & -28 \\
\hline & & & L parahippocampal gyrus & 6 & -2.86 & -24 & -8 & -32 \\
\hline
\end{tabular}

Note. Only the regions included in the 10-15 most stable clusters per LV are presented in this table (LV1:

$|\mathrm{BSR}| \geq 2.1$, Cluster Size $\geq 10 ; \mathrm{LV} 2:|\mathrm{BSR}| \geq 2.4$, Cluster Size $\geq 10$ ). ER = early remitter, LR = late

remitter, $\mathrm{NR}=$ non-remitter, $\mathrm{BSR}=$ bootstrap ratio, $\mathrm{R}=$ right, $\mathrm{L}=$ left.

Early, late and non-remitter comparison - dorsolateral prefrontal cortex ROI

The PLS analysis comparing early, late and non-remitters in connectivity between the dlPFC ROI and the rest of the brain did not identify any significant LVs highlighting differences between patient groups.

\section{Subsample replication}

To assess the stability of our patient group comparisons, we ran additional PLS analyses on the largest single-site population of patients (16 ER, $12 \mathrm{LR}, \& 18 \mathrm{NR}$, from the UBC site). Specifically, we used non-rotated (i.e. hypothesis-driven) PLS to test whether the group differences we identified in the main analyses with the ACC, PCC and insula ROI, were present in this subsample (one each for the ACC and 
PCC, two for the insula ROI). In addition to inspecting the analysis results visually, we correlated the stable ( $|\mathrm{BSR}| \geq 2$ ) element loadings of the main analyses with those of the subsample analyses to assess their similarity. As these were post-hoc analyses, we applied Bonferroni correction to the results. The results are summarized in Table 6. Two out of the four LVs tested were significant according to the Bonferroni corrected $\mathrm{p}$-value $(p<.013)$, one fell into the uncorrected window of significance $(p=.043)$, and one showed a trend towards significance $(p=.092)$. Correlations between stable element loadings ranged between .80 and .90 .

Table 6. Significance and Correlation of Subsample Replication Analyses for Each Subsample and Seed ROI

\section{Seed ROI LV Significance Correlation with full sample analysis pattern}

\begin{tabular}{lcll}
\hline ACC ROI & 1 & $p=.092$ & $r=.80$ \\
PCC ROI & 1 & $p=.007^{* *}$ & $r=.90$ \\
INS ROI & 1 & $p=.010^{* *}$ & $r=.90$ \\
INS ROI & 2 & $p=.043^{*}$ & $r=.87$
\end{tabular}

** Significant at Bonferroni corrected $\mathrm{p}$-value $<.013, *$ Significant at uncorrected $\mathrm{p}$-value $<.05 . \mathrm{ROI}=$ region of interest, $\mathrm{LV}=$ latent variable, $\mathrm{ACC}=$ anterior cingulate cortex, $\mathrm{PCC}=$ posterior cingulate cortex, INS $=$ insula.

Post-hoc analysis examining remission to escitalopram alone or combined escitalopram and aripiprazole To test whether the differences observed in insula connectivity between early and late remitters (see Early, late and non-remitter comparison - insula ROI) were related to differences in the medication regimen received (see Table 2), we ran a PLS analysis examining differences in insula connectivity between remitters to escitalopram alone $(\mathrm{N}=33)$ and remitters to combined escitalopram and aripiprazole $(\mathrm{N}=49)$. This revealed one significant LV differentiating between the two groups $(\mathrm{p}<.001, \mathrm{PCCE}=$ $37.4 \%$ ), indicating that, before treatment, participants remitting to escitalopram alone most consistently 
medRxiv preprint doi: https://doi.org/10.1101/2021.01.27.21250490; this version posted January 29, 2021. The copyright holder for this preprint (which was not certified by peer review) is the author/funder, who has granted medRxiv a license to display the preprint in perpetuity.

It is made available under a CC-BY-NC 4.0 International license .

showed stronger connectivity between the insula ROI and medial and anterior PFC areas and the dorsal ACC (see Table S5 \& Figure S1) compared to participants who remitted to combined escitalopram and aripiprazole.

\section{Discussion}

We aimed to replicate and extend previous findings linking abnormal fMRI connectivity in three major resting state networks to the depressed state and antidepressant treatment outcomes using a large, wellcharacterized, multi-site sample. Overall, we were able to replicate the more robust differences between patients with MDD and controls highlighted in previous reviews [4, 5]. In addition, we identified differences in connectivity within and between these same networks within the patient population. ACC connectivity differentiated early from late and non-remitters, PCC connectivity distinguished early, late and non-remitters, and insula connectivity revealed both early/late remitter and remitter/non-remitter contrasts. Importantly, these differentiating connectivity patterns held in a single-site subsample, indicating a degree of stability of these group differences. As we looked at the relationship between connectivity before the start of treatment and remission status after 16 weeks of pharmacotherapy, these patterns might be useful in predicting antidepressant treatment outcomes.

In line with previous literature $[4,5]$, we found stronger connectivity within the DMN, most notably in the anterior subnetwork, and between the anterior DMN and the CCN and SN, and weaker connectivity within the $\mathrm{CCN}$ in patients as compared to controls. We also found weaker connectivity between the posterior DMN and the $\mathrm{CCN}$ and $\mathrm{SN}$ in patients, but this contrast only approached significance. Interestingly, altered connectivity between the anterior DMN and the SN, and the DMN and the CCN, was only apparent when using DMN regions as seeds (ACC \& PCC ROIs). This could indicate that DMN abnormalities are stronger and thus most useful in distinguishing patients from controls. While the DMN certainly takes a prominent place in the literature on brain network alterations related to MDD, so do the two other networks investigated in this project. An alternative interpretation might be that DMN 
medRxiv preprint doi: https://doi.org/10.1101/2021.01.27.21250490; this version posted January 29, 2021. The copyright holder for this preprint (which was not certified by peer review) is the author/funder, who has granted medRxiv a license to display the preprint in perpetuity. It is made available under a CC-BY-NC 4.0 International license .

effects were stronger because we recorded data during resting state, when the DMN is typically active, while both the $\mathrm{CCN}$ and $\mathrm{SN}$ are typically more active during tasks [46].

In addition to these expected effects, the connectivity patterns differentiating patients and controls included connections that have not been highlighted in previous reviews. Most interestingly, we identified stronger connectivity between CCN and SN regions in patients using both the CCN and SN seeds (dIPFC and insula, respectively). Few studies have found altered connectivity between the CCN and SN directly (e.g. [47]). However, these two networks are involved in emotion processing and mood regulation, which have been found to be abnormal in patients with MDD (e.g. [48]), therefore our finding of aberrant connectivity between them is not surprising. Mulders et al. [4] mention that the SN is less well-defined during resting state (in comparison to the $\mathrm{DMN}$ and $\mathrm{CCN}$ ), so effects might be harder to detect for this network, especially with small samples. Our finding of increased connectivity between the SN and CCN in a larger sample, together with the potential functional relevance of these connections, indicates that SN-CCN connectivity should be studied in more detail in future research. In addition, several regions outside of our networks of interest were highlighted by our analyses, including areas related to visual and motor processing. While generally given little attention, such regions have been observed in previous studies examining differences between patients with MDD and controls [4, 5], indicating that network alterations associated with MDD are more widespread than is generally highlighted.

Nonetheless, the three selected networks revealed important baseline connectivity differences between patients who reached remission early (within 8 weeks of treatment) or late (within 16 weeks), or who did not reach remission over the course of this study. Early remitters displayed weaker connectivity within the anterior DMN, and between the ACC seed and regions from the $\mathrm{CCN}$ and SN compared to both late and non-remitters. The ACC has been proposed to play a central role in MDD pathology [4951]. While the subgenual part of the ACC is most often highlighted, the pregenual ACC, where our seed was located, has also been found to be part of the altered DMN in MDD and associated with treatment effects $[52,53]$. Our finding that ACC connectivity with regions from both other networks differentiates 
medRxiv preprint doi: https://doi.org/10.1101/2021.01.27.21250490; this version posted January 29, 2021. The copyright holder for this preprint (which was not certified by peer review) is the author/funder, who has granted medRxiv a license to display the preprint in perpetuity. It is made available under a CC-BY-NC 4.0 International license .

patients with different treatment outcomes further supports this idea and highlights the potential of this feature for predicting early remission in response to pharmacotherapy.

The connectivity pattern of the posterior DMN seed differentiated all three groups, with early remitters showing the strongest connectivity within the posterior DMN and between the PCC seed and other cingulate areas, while non-remitters exhibited the weakest connectivity between these regions, and late remitters showed intermediate connectivity strengths. The finding that both stronger and weaker connectivity within the DMN was associated with (early) remission might be explained by the observation that the anterior and posterior DMN subnetworks respond differently to pharmacotherapy [38]. Li et al. [38] found that DMN connectivity was increased in patients before treatment in both subnetworks, but only decreased with pharmacotherapy in the posterior DMN. This is consistent with the idea that the stronger posterior DMN connectivity we observed in early and late remitters prior to treatment is one of the MDD-related abnormalities that pharmacotherapy has an effect on. Importantly, the fact that we observed this group difference at baseline suggests that PCC connectivity could be a predictor of treatment success.

With the insula as seed (i.e. focusing on the SN), we identified two connectivity patterns: one distinguishing early and late remitters, and one distinguishing remitters (early and late) from nonremitters. The first connectivity pattern included stronger connectivity in late remitters within the SN (between bilateral insulae) and weaker connectivity between the insula seed and regions from the other two networks (e.g. PCC, dlPFC). Connectivity between limbic SN and frontal CCN regions has often been highlighted as showing treatment-relevant effects [6-8]. In fact, it has been proposed that the right anterior insula acts as a switch between the DMN and CCN, and behaves aberrantly in the context of MDD [54]. While our seed was located in the left anterior insula, our finding of weaker connectivity between the insula seed and the other two networks implies that, in our study as well, the interactions between the SN, DMN and CCN were important for remission. This effect might be specifically related to remission to the aripiprazole add-on many late remitters received, as early remitters, who only received escitalopram for the duration of the study, did not show this effect. Our follow-up analysis comparing 
medRxiv preprint doi: https://doi.org/10.1101/2021.01.27.21250490; this version posted January 29, 2021. The copyright holder for this preprint (which was not certified by peer review) is the author/funder, who has granted medRxiv a license to display the preprint in perpetuity. It is made available under a CC-BY-NC 4.0 International license .

remitters to escitalopram alone and remitters to combined escitalopram and aripiprazole revealed some overlap with the early/late remitter contrast, most notably showing weaker connectivity between the insula seed and the anterior DMN (i.e. the $\mathrm{mPFC}$ ) in both late remitters and remitters to combined escitalopram and aripiprazole. The second contrast further highlighted the importance of SN - DMN connectivity for both early and late remission, with stronger connectivity between the insula seed and the mPFC and the left angular gyrus at baseline being associated with remission.

In addition, this second pattern included multiple cerebellar areas whose connectivity with the insula seed differentiated remitters and non-remitters. Although the cerebellum was not the focus of our study, it showed up in most of our analyses as contributing to the differences between patients and controls, and different patient groups. While the cerebellum has traditionally been associated with motor function, this part of the brain is increasingly recognized as a structure playing an important role in a diverse set of processes and disorders, including the pathology and treatment of MDD [55-57]. Indeed, most of our analyses revealed connections between our seeds and regions in the posterior lobe of the cerebellum (lobule VI-IX), which have more specifically been related to non-motor functions (e.g. cognitive and affective; [55]). The remitter/non-remitter contrast in insula connectivity, which showed the most prominent involvement of the cerebellum in our analyses, revealed greater connectivity between the insula seed and lobule VI, VIIA (crus I \& II) and VIII of the cerebellum. Lobule VI has been associated with affective processing, and crus I and II of lobule VIIA have been related to the DMN and CCN, once again pointing towards the importance of networks involved with emotion processing and mood regulation for antidepressant treatment effects.

Interestingly, the analysis with the dlPFC as the seed region (from the $\mathrm{CCN}$ ) did not reveal any differences among the three patient groups. Previous findings of CCN connectivity have been inconsistent, with some proposing that MDD-related alterations in CCN connectivity might not be sensitive to treatment with antidepressant medication [7]. An alternative interpretation, in line with the fact that $\mathrm{CCN}$ regions did show up in our analyses with seeds from the other networks, is that $\mathrm{CCN}$ 
medRxiv preprint doi: https://doi.org/10.1101/2021.01.27.21250490; this version posted January 29, 2021. The copyright holder for this preprint (which was not certified by peer review) is the author/funder, who has granted medRxiv a license to display the preprint in perpetuity.

It is made available under a CC-BY-NC 4.0 International license .

connectivity is only weakly related to pharmacotherapeutic effects (e.g. through its connections with other networks).

To test the stability of our findings, we performed post-hoc analyses for the three seed regions (ACC, PCC and insula) that revealed differences between early- late- and/or non-remitters on the largest single-site dataset to exclude the possibility that our findings might have been unduly influenced by intersite variability (e.g. due to data being collected using different scanners). Half of the contrasts survived significance testing with correction for multiple comparisons, and all showed trends toward significance and revealed similar patterns of connectivity as observed in the main analyses. These findings suggest that the baseline differences we observed between our three patient groups have a degree of stability, are not dependent on a specific site/scanner setup and are therefore more likely to generalize to other samples. The lack of significance of part of our post-hoc tests is likely related to the smaller sample size used in these analyses.

While our study addressed certain issues relating to reproducibility and generalizability, such as sample size and scanner differences, other factors fell outside the scope of this paper. For example, individual variation in the expression of MDD and response to antidepressant treatment among patients has also been proposed to play a role in the difficulty of finding robust (neuroimaging) biomarkers [6, 58]. Although the bootstrapping procedure in PLS analyses ensures that the identified patterns of connectivity show a degree of stability across participants, this approach is not designed to determine if these findings might apply at an individual patient level. Thus, exploring whether these potential markers of treatment outcome translate to individual patients would be a worthwhile next step towards clinical applications. Similarly, other sources of variance, such as demographic and clinical characteristics and the use of different methodology, have been related to variable findings $[5,6,58]$, and could be explored in more detail in future studies. 


\section{Limitations}

Our study had several limitations that deserve consideration. First, the treatment regimen differed between early remitters (by definition recipients of escitalopram monotherapy), and among late and nonremitters, who received either escitalopram alone or with adjunctive aripiprazole. While early remitters only received escitalopram, both late and non-remitters included individuals who received either escitalopram alone, or escitalopram and aripiprazole together, making it hard to disentangle specific medication effects. While suboptimal, this is common and difficult to avoid in clinical research on MDD, as the use of multiple medications and individually adjusted regimens are standard treatment practice.

Second, connectivity can be quantified in multiple ways, and using different approaches has been related to the variable findings reported in the literature. We chose seed-based correlation because it is the most commonly used method, and it has shown a greater degree of stability when compared to other metrics of connectivity [59], but it does have its own disadvantages. For example, by correlating a few seeds selected a priori with the rest of the voxels in the brain, our analyses focused on a limited set of connections in the brain, meaning that relevant connections could have been missed. In addition, even within the category of seed-based correlation there are different approaches to calculate connectivity, and the one we used (across-subject cross-correlation) is different from the one employed by Fiecas and colleagues [59] (within-subject cross-correlation, see [60] for details on the difference between these two approaches). Lastly, we selected the ACC as the anterior DMN seed, because this area appears to play a key role in the pathology and treatment of MDD and is most commonly selected as anterior DMN seed in seed-based connectivity studies of MDD $[4,50]$. However, this region might only be included in the DMN in patients with MDD [9], and might therefore have skewed our comparison of MDD and control participants for this seed.

\section{Conclusion}

Here we replicated and extended abnormal patterns of fMRI connectivity in patients with MDD compared to controls, as well as connectivity characteristics measured before the start of treatment associated with 
medRxiv preprint doi: https://doi.org/10.1101/2021.01.27.21250490; this version posted January 29, 2021. The copyright holder for this preprint

(which was not certified by peer review) is the author/funder, who has granted medRxiv a license to display the preprint in perpetuity.

It is made available under a CC-BY-NC 4.0 International license .

remission status after 16 weeks of antidepressant treatment. Our replication of connectivity differences between patients and controls confirmed the importance of the DMN, SN and CCN for MDD pathology, and revealed additional stronger connections between the $\mathrm{SN}$ and $\mathrm{CCN}$ in patients. Our patient group analyses further revealed multiple patterns of connectivity within and between the DMN, SN and CCN that were associated with remission status. Interestingly, different seeds highlighted different group characteristics, indicating that multiple networks need to be considered to get a full picture of the connectivity differences between early, late and non-remitters to pharmacotherapy. Specifically, ACC connectivity revealed a pattern that was specific to early remitters, while insula connectivity revealed a late-remitter and remitter effect and PCC connectivity distinguished all three groups. Although reproducibility and generalizability are still major concerns in current neuroimaging research, the fact that we were able to replicate previous single-site findings in a larger, multi-site sample (with MRI data collected from different Tesla scanners), and demonstrate stability in the patterns differentiating patients based on remission status in a single-site subsample of our data is encouraging and supports the potential of our findings for future clinical use. 
medRxiv preprint doi: https://doi.org/10.1101/2021.01.27.21250490; this version posted January 29, 2021. The copyright holder for this preprint (which was not certified by peer review) is the author/funder, who has granted medRxiv a license to display the preprint in perpetuity. It is made available under a CC-BY-NC 4.0 International license .

\section{Funding and disclosures}

CAN-BIND is an Integrated Discovery Program carried out in partnership with, and financial support from, the Ontario Brain Institute, an independent non-profit corporation, funded partially by the Ontario government. The opinions, results and conclusions are those of the authors and no endorsement by the Ontario Brain Institute is intended or should be inferred. Additional funding is provided by the Canadian Institutes of Health Research (CIHR), Lundbeck, and Servier. Funding and/or in-kind support is also provided by the investigators' universities and academic institutions. All study medications are independently purchased at wholesale market values. We acknowledge support to GW in the form of a Mamdani Family Foundation Graduate Scholarship and Alberta Graduate Excellence Scholarship (AGES: International). RM has received consulting and speaking honoraria from AbbVie, Allergan, Janssen, KYE, Lundbeck, Otsuka, and Sunovion, and research grants from CAN-BIND, CIHR, Janssen, Lallemand, Lundbeck, Nubiyota, OBI and OMHF. RWL has received honoraria or research funds from Allergan, Manuscript File 2Asia-Pacific Economic Cooperation, BC Leading Edge Foundation, CIHR, CANMAT, Canadian Psychiatric Association, Hansoh, Healthy Minds Canada, Janssen, Lundbeck, Lundbeck Institute, Michael Smith Foundation for Health Research, MITACS, Ontario Brain Institute, Otsuka, Pfizer, St. Jude Medical, University Health Network Foundation, and VGH-UBCH Foundation. BNF received a research grant from Pfizer, outside of this work. SR has received grant funding from the Ontario Brain Institute and Canadian Institutes of Health Research and holds a patent Teneurin CTerminal Associated Peptides (TCAP) and methods and uses thereof. Inventors: David Lovejoy, R.B. Chewpoy, Dalia Barsyte, Susan Rotzinger. SHK has received research funding or honoraria from the following sources: Abbott, Alkermes, Allergan, BMS, Brain Canada, Canadian Institutes for Health Research (CIHR), Janssen, Lundbeck, Lundbeck Institute, Ontario Brain Institute, Ontario Research Fund (ORF), Otsuka, Pfizer, Servier, Sunovion and Xian-Janssen. SCS reports partial support from Canadian Biomarker Integration Network in Depression and CIHR (MOP 137097) grants during the conduct of the study, and grants from Ontario Brain Institute, Canadian Foundation for Innovation and Brain Canada, outside the submitted work. He is also the chief scientific officer of the neuroimaging data analysis 
company ADMdx, Inc (www. admdx.com), which specializes in brain image analysis to enable diagnosis, prognosis and drug effect detection for Alzheimer disease and various other forms of dementia. JKH, SH, ADD, MZ, GBH, DJM, GMM and ABP have no funding or potential conflicts of interest to disclose.

\section{Acknowledgements}

We would like to thank Keith Ho for his help with organizing the clinical data, and all the patients, controls, and health care workers involved in this project for the generous contribution of their time and their participation in this work.

\section{Author contributions}

GW: Data analysis and interpretation, writing (original draft), writing (review, editing, and approval); JKH: Data collection, data curation, writing (review, editing, and approval); SH: Data collection, data curation, writing (review, editing, and approval); ADD: Data collection, data curation, writing (review, editing, and approval); MZ: Data collection, data curation, writing (review, editing, and approval); SRA: Data curation, writing (review, editing, and approval); RM: Study concept, data collection, writing(review, editing, and approval); RWL: Study concept, data collection, writing (review, editing, and approval); BNF: Study concept, data collection, data curation, writing (review, editing, and approval); GBH: Study concept, data collection, data curation, writing (review, editing, and approval); DJM: Study concept, data collection, data curation, writing (review, editing, and approval); SR: Study concept, data collection, data curation, writing (review, editing, and approval); SHK: Study concept, data collection, writing (review, editing, and approval); SCS: Data curation, writing (review, editing, and approval); GMM: Study concept, data collection, data curation; ABP: Data analysis, writing (original draft), writing (review, editing, and approval). 
medRxiv preprint doi: https://doi.org/10.1101/2021.01.27.21250490; this version posted January 29, 2021. The copyright holder for this preprint (which was not certified by peer review) is the author/funder, who has granted medRxiv a license to display the preprint in perpetuity. It is made available under a CC-BY-NC 4.0 International license.

\section{Data availability statement}

The data analyzed in this paper are not publicly available, but may be made available if permission is granted by the CAN-BIND Investigator's Team and Ontario Brain Institute upon reasonable request. 
medRxiv preprint doi: https://doi.org/10.1101/2021.01.27.21250490; this version posted January 29, 2021. The copyright holder for this preprint (which was not certified by peer review) is the author/funder, who has granted medRxiv a license to display the preprint in perpetuity.

It is made available under a CC-BY-NC 4.0 International license .

\section{References}

1. Cuijpers, P., A. Stringaris, and M. Wolpert, Treatment outcomes for depression: challenges and opportunities. Lancet Psychiatry, 2020. 7(11): p. 925-927.

2. Rush, A.J., et al., Acute and longer-term outcomes in depressed outpatients requiring one or several treatment steps: a STAR*D report. Am J Psychiatry, 2006. 163(11): p. 1905-17.

3. $\quad$ Poldrack, R.A., et al., Scanning the horizon: towards transparent and reproducible neuroimaging research. Nat Rev Neurosci, 2017. 18(2): p. 115-126.

4. Mulders, P.C., et al., Resting-state functional connectivity in major depressive disorder: A review. Neurosci Biobehav Rev, 2015. 56: p. 330-44.

5. Kaiser, R.H., et al., Large-Scale Network Dysfunction in Major Depressive Disorder: A Metaanalysis of Resting-State Functional Connectivity. JAMA Psychiatry, 2015. 72(6): p. 603-11.

6. Dichter, G.S., D. Gibbs, and M.J. Smoski, A systematic review of relations between resting-state functional-MRI and treatment response in major depressive disorder. J Affect Disord, 2015. 172: p. 8-17.

7. Gudayol-Ferre, E., et al., Changes in brain connectivity related to the treatment of depression measured through fMRI: a systematic review. Front Hum Neurosci, 2015. 9: p. 582.

8. Brakowski, J., et al., Resting state brain network function in major depression - Depression symptomatology, antidepressant treatment effects, future research. J Psychiatr Res, 2017. 92: p. 147-159.

9. Zhou, Y., et al., Increased neural resources recruitment in the intrinsic organization in major depression. J Affect Disord, 2010. 121(3): p. 220-30.

10. Boly, M., et al., Intrinsic brain activity in altered states of consciousness: how conscious is the default mode of brain function? Ann N Y Acad Sci, 2008. 1129: p. 119-29.

11. Rayner, G., G. Jackson, and S. Wilson, Cognition-related brain networks underpin the symptoms of unipolar depression: Evidence from a systematic review. Neurosci Biobehav Rev, 2016. 61: p. 53-65. 
medRxiv preprint doi: https://doi.org/10.1101/2021.01.27.21250490; this version posted January 29, 2021. The copyright holder for this preprint (which was not certified by peer review) is the author/funder, who has granted medRxiv a license to display the preprint in perpetuity. It is made available under a CC-BY-NC 4.0 International license .

12. Goldberg, D., The heterogeneity of “major depression”. World Psychiatry, 2011. 10(3): p. 226.

13. Kessler, R., et al., Using patient self-reports to study heterogeneity of treatment effects in major depressive disorder. Epidemiology and psychiatric sciences, 2017. 26(1): p. 22-36.

14. Gong, Q. and Y. He, Depression, neuroimaging and connectomics: a selective overview. Biol Psychiatry, 2015. 77(3): p. 223-235.

15. Button, K.S., et al., Power failure: why small sample size undermines the reliability of neuroscience. Nat Rev Neurosci, 2013. 14(5): p. 365-76.

16. Long, Z., et al., Prediction on treatment improvement in depression with resting state connectivity: A coordinate-based meta-analysis. J Affect Disord, 2020. 276: p. 62-68.

17. Lam, R.W., et al., Discovering biomarkers for antidepressant response: protocol from the Canadian biomarker integration network in depression (CAN-BIND) and clinical characteristics of the first patient cohort. BMC Psychiatry, 2016. 16: p. 105.

18. Kennedy, S.H., et al., Symptomatic and Functional Outcomes and Early Prediction of Response to Escitalopram Monotherapy and Sequential Adjunctive Aripiprazole Therapy in Patients With Major Depressive Disorder: A CAN-BIND-1 Report. J Clin Psychiatry, 2019. 80(2).

19. Montgomery, S.A. and M. Asberg, A new depression scale designed to be sensitive to change. $\mathrm{Br}$ J Psychiatry, 1979. 134: p. 382-9.

20. McIntosh, A.R. and N.J. Lobaugh, Partial least squares analysis of neuroimaging data: applications and advances. Neuroimage, 2004. 23: p. S250-S263.

21. Sheehan, D.V., et al., The Mini-International Neuropsychiatric Interview (M.I.N.I.): the development and validation of a structured diagnostic psychiatric interview for DSM-IV and ICD-10. J Clin Psychiatry, 1998. 59 Suppl 20: p. 22-33; quiz 34-57.

22. Williams, J.B. and K.A. Kobak, Development and reliability of a structured interview guide for the Montgomery Asberg Depression Rating Scale (SIGMA). Br J Psychiatry, 2008. 192(1): p. 528. 
medRxiv preprint doi: https://doi.org/10.1101/2021.01.27.21250490; this version posted January 29, 2021. The copyright holder for this preprint (which was not certified by peer review) is the author/funder, who has granted medRxiv a license to display the preprint in perpetuity. It is made available under a CC-BY-NC 4.0 International license .

23. Zimmerman, M., M.A. Posternak, and I. Chelminski, Derivation of a definition of remission on the Montgomery-Asberg depression rating scale corresponding to the definition of remission on the Hamilton rating scale for depression. J Psychiatr Res, 2004. 38(6): p. 577-82.

24. Dupuy, J.M., et al., A critical review of pharmacotherapy for major depressive disorder. Int J Neuropsychopharmacol, 2011. 14(10): p. 1417-31.

25. Lecrubier, Y., How do you define remission? Acta Psychiatr Scand Suppl, 2002(415): p. 7-11.

26. Thase, M.E., Achieving remission and managing relapse in depression. J Clin Psychiatry, 2003. 64 Suppl 18: p. 3-7.

27. Albert, J., S. Lopez-Martin, and L. Carretie, Emotional context modulates response inhibition: neural and behavioral data. Neuroimage, 2010. 49(1): p. 914-21.

28. MacQueen, G.M., et al., The Canadian Biomarker Integration Network in Depression (CANBIND): magnetic resonance imaging protocols. J Psychiatry Neurosci, 2019. 44(4): p. 223-236.

29. Churchill, N.W., et al., An Automated, Adaptive Framework for Optimizing Preprocessing Pipelines in Task-Based Functional MRI. PLoS One, 2015. 10(7): p. e0131520.

30. Churchill, N.W., et al., Optimizing fMRI preprocessing pipelines for block-design tasks as a function of age. Neuroimage, 2017. 154: p. 240-254.

31. Campbell, K.L., et al., Age differences in the intrinsic functional connectivity of default network subsystems. Front Aging Neurosci, 2013. 5: p. 73.

32. Churchill, N.W. and S.C. Strother, PHYCAA+: an optimized, adaptive procedure for measuring and controlling physiological noise in BOLD fMRI. Neuroimage, 2013. 82: p. 306-25.

33. Carbonell, F., P. Bellec, and A. Shmuel, Global and system-specific resting-state fMRI fluctuations are uncorrelated: principal component analysis reveals anti-correlated networks. Brain Connect, 2011. 1(6): p. 496-510.

34. Churchill, N.W., et al., Optimizing preprocessing and analysis pipelines for single-subject fMRI. I. Standard temporal motion and physiological noise correction methods. Hum Brain Mapp, 2012. 33(3): p. 609-27. 
medRxiv preprint doi: https://doi.org/10.1101/2021.01.27.21250490; this version posted January 29, 2021. The copyright holder for this preprint (which was not certified by peer review) is the author/funder, who has granted medRxiv a license to display the preprint in perpetuity. It is made available under a CC-BY-NC 4.0 International license .

35. Churchill, N.W., et al., Optimizing preprocessing and analysis pipelines for single-subject fMRI: 2. Interactions with ICA, PCA, task contrast and inter-subject heterogeneity. PLoS One, 2012. 7(2): p. e31147.

36. Calhoun, V.D., et al., The impact of T1 versus EPI spatial normalization templates for fMRI data analyses. Hum Brain Mapp, 2017. 38(11): p. 5331-5342.

37. Drysdale, A.T., et al., Resting-state connectivity biomarkers define neurophysiological subtypes of depression. Nature medicine, 2017. 23(1): p. 28.

38. Li, B., et al., A treatment-resistant default mode subnetwork in major depression. Biol Psychiatry, 2013. 74(1): p. 48-54.

39. Chikazoe, J., Localizing performance of go/no-go tasks to prefrontal cortical subregions. Curr Opin Psychiatry, 2010. 23(3): p. 267-72.

40. Shafritz, K.M., S.H. Collins, and H.P. Blumberg, The interaction of emotional and cognitive neural systems in emotionally guided response inhibition. Neuroimage, 2006. 31(1): p. 468-75.

41. McIntosh, A.R. and N.J. Lobaugh, Partial least squares analysis of neuroimaging data: applications and advances. Neuroimage, 2004. 23 Suppl 1: p. S250-63.

42. Tzourio-Mazoyer, N., et al., Automated anatomical labeling of activations in SPM using a macroscopic anatomical parcellation of the MNI MRI single-subject brain. Neuroimage, 2002. 15(1): p. 273-89.

43. Oostenveld, R., et al., FieldTrip: open source software for advanced analysis of MEG, EEG, and invasive electrophysiological data. Computational intelligence and neuroscience, 2011. 2011.

44. Talairach, J., Tournoux, P., Co-planar stereotaxic atlas of the human brain. 1988, New York: Thieme Medical Publishers, Inc.

45. Xia, M., J. Wang, and Y. He, BrainNet Viewer: a network visualization tool for human brain connectomics. PLoS One, 2013. 8(7): p. e68910. 
medRxiv preprint doi: https://doi.org/10.1101/2021.01.27.21250490; this version posted January 29, 2021. The copyright holder for this preprint (which was not certified by peer review) is the author/funder, who has granted medRxiv a license to display the preprint in perpetuity. It is made available under a CC-BY-NC 4.0 International license .

46. Nickerson, L.D., Replication of Resting State-Task Network Correspondence and Novel Findings on Brain Network Activation During Task fMRI in the Human Connectome Project Study. Sci Rep, 2018. 8(1): p. 17543.

47. Pang, Y., et al., Transdiagnostic and diagnosis-specific dynamic functional connectivity anchored in the right anterior insula in major depressive disorder and bipolar depression. Prog Neuropsychopharmacol Biol Psychiatry, 2018. 85: p. 7-15.

48. Park, C., et al., The neural systems of emotion regulation and abnormalities in major depressive disorder. Behav Brain Res, 2019.367: p. 181-188.

49. Hamani, C., et al., The subcallosal cingulate gyrus in the context of major depression. Biol Psychiatry, 2011. 69(4): p. 301-8.

50. Pizzagalli, D.A., Frontocingulate dysfunction in depression: toward biomarkers of treatment response. Neuropsychopharmacology, 2011.36(1): p. 183-206.

51. Mayberg, H.S., et al., Deep brain stimulation for treatment-resistant depression. Neuron, 2005. 45(5): p. 651-60.

52. Jing, Y., et al., Pregenual or subgenual anterior cingulate cortex as potential effective region for brain stimulation of depression. Brain Behav, 2020. 10(4): p. e01591.

53. Peng, X., et al., Sub-regional anterior cingulate cortex functional connectivity revealed default network subsystem dysfunction in patients with major depressive disorder. Psychol Med, 2020: p. $1-9$.

54. Manoliu, A., et al., Insular dysfunction within the salience network is associated with severity of symptoms and aberrant inter-network connectivity in major depressive disorder. Front Hum Neurosci, 2013. 7: p. 930.

55. Depping, M.S., et al., Cerebellar contributions to major depression. Frontiers in psychiatry, 2018. 9: p. 634.

56. Minichino, A., et al., The role of cerebellum in unipolar and bipolar depression: a review of the main neurobiological findings. Rivista di Psichiatria, 2014. 49(3): p. 124-131. 
medRxiv preprint doi: https://doi.org/10.1101/2021.01.27.21250490; this version posted January 29, 2021. The copyright holder for this preprint (which was not certified by peer review) is the author/funder, who has granted medRxiv a license to display the preprint in perpetuity. It is made available under a CC-BY-NC 4.0 International license .

57. Konarski, J.Z., et al., Is the cerebellum relevant in the circuitry of neuropsychiatric disorders? J Psychiatry Neurosci, 2005. 30(3): p. 178-86.

58. Wise, T., et al., Diagnostic and therapeutic utility of neuroimaging in depression: an overview. Neuropsychiatr Dis Treat, 2014. 10: p. 1509-22.

59. Fiecas, M., et al., Quantifying temporal correlations: a test-retest evaluation of functional connectivity in resting-state fMRI. Neuroimage, 2013. 65: p. 231-41.

60. Roberts, R.P., et al., The Simpson's paradox and fMRI: Similarities and differences between functional connectivity measures derived from within-subject and across-subject correlations. Neuroimage, 2016. 135: p. 1-15. 